\title{
A Review of Convex Approaches for Control, Observation and Safety of Linear Parameter Varying and Takagi-Sugeno Systems
}

\author{
Francisco-Ronay López-Estrada ${ }^{1, *,+}\left(\mathbb{C}\right.$, Damiano Rotondo ${ }^{2,3, *,+}$ (i) and \\ Guillermo Valencia-Palomo ${ }^{4, *,+}$ (i) \\ 1 TURIX-Dynamics Diagnosis and Control Group, Tecnológico Nacional de México/Instituto Tecnológico de \\ Tuxtla Gutiérrez, Carretera Panamericana km 1080, C.P. 29050 Tuxtla Gutierrez, Mexico \\ 2 Institut de Robòtica i Informàtica Industrial, CSIC-UPC, Llorens i Artigas 4-6, 08028 Barcelona, Spain \\ 3 Research Center for Supervision, Safety and Automatic Control, Universitat Politècnica de Catalunya (UPC), \\ Rambla Sant Nebridi, 22, 08022 Terrassa, Spain \\ 4 Tecnológico Nacional de México/Instituto Tecnológico de Hermosillo, Av. Tecnológico y Periférico Poniente, \\ S/N, 83170 Hermosillo, Sonora, Mexico \\ * Correspondence: frlopez@ittg.edu.mx (F.-R.L.-E.); damiano.rotondo@upc.edu (D.R.); \\ gvalencia@ith.mx (G.V.-P.) \\ + These authors contributed equally to this work.
}

Received: 25 September 2019; Accepted: 30 October 2019; Published: 4 November 2019

check for updates

\begin{abstract}
This paper provides a review about the concept of convex systems based on Takagi-Sugeno, linear parameter varying (LPV) and quasi-LPV modeling. These paradigms are capable of hiding the nonlinearities by means of an equivalent description which uses a set of linear models interpolated by appropriately defined weighing functions. Convex systems have become very popular since they allow applying extended linear techniques based on linear matrix inequalities (LMIs) to complex nonlinear systems. This survey aims at providing the reader with a significant overview of the existing LMI-based techniques for convex systems in the fields of control, observation and safety. Firstly, a detailed review of stability, feedback, tracking and model predictive control (MPC) convex controllers is considered. Secondly, the problem of state estimation is addressed through the design of proportional, proportional-integral, unknown input and descriptor observers. Finally, safety of convex systems is discussed by describing popular techniques for fault diagnosis and fault tolerant control (FTC).
\end{abstract}

Keywords: linear parameter varying (LPV) systems; Takagi-Sugeno systems; convex systems; linear matrix inequalities (LMIs); fault diagnosis; fault tolerant control (FTC)

\section{Introduction}

Confucius once said "the beginning of wisdom is to call things by their proper name". In this regard, it can be noticed that within the control community there is a big disagreement to call a certain class of multiple model systems by its proper name, in other words, to call a spade a spade. Multiple models were proposed in order to reduce the complexity of controller design for nonlinear systems by describing the latter as a combination of local linear models. To this end, several approaches have been proposed in the literature to deal with this problem, such as the linear parameter varying (LPV), the quasi-LPV (qLPV) and the Takagi-Sugeno (TS).

LPV systems were introduced by Refs. [1,2] as models used to design controllers that guarantee a suitable closed-loop performance for nonlinear plants working under time-varying operating conditions. This was achieved by embedding the plant's nonlinearities inside the so-called scheduling 
parameters. The term LPV was coined to differentiate the resulting class of systems from both linear time invariant (LTI) and linear time varying (LTV) systems. The difference with respect to LTI systems is clear because LPV systems are non-stationary. On the other hand, LPV systems are distinguished from LTV systems in the perspective taken on both analysis and synthesis. LPV systems can be seen as a generalization of a group of LTV systems, each one obtained by means of a predetermined trajectory of the weighing functions. Therefore, properties such as stability, disturbance rejection and tracking, among others, hold for a family of LTV systems, rather than for a single LTV system [3]. A typical LPV system is described by:

$$
\begin{aligned}
& \dot{x}(t)=A(\theta(t)) x(t)+B(\theta(t)) u(t) \\
& y(t)=C(\theta(t)) x(t)
\end{aligned}
$$

where $x(t) \in \mathbb{R}^{n_{x}}$ denotes the state vector, $u(t) \in \mathbb{R}^{n_{u}}$ is the input vector, $y(t) \in \mathbb{R}^{n_{y}}$ is the output vector and $\theta(t) \in \mathbb{R}^{n_{\theta}}$ is the vector of varying parameters, which can be a function of exogenous or endogenous variables (in the latter case, the system is referred to as quasi-LPV) and that takes values within a region $\Theta$, that is, $\theta(t) \in \Theta \subset \mathbb{R}^{n_{\theta}}$.

TS models are similar to LPV systems, since they are obtained by considering some collection of linear models, although their overall blending is obtained by means of a set of fuzzy IF ... THEN rules [4]. At first, they were obtained by performing linearization of the nonlinear plant about different operating points [5]. Nevertheless, this conception was changed in the work by Ohtake et al. [6], who proposed a convex modeling technique via the so-called sector nonlinearity approach. In this case, the main idea is to obtain a convex system such that the global model matches the nonlinear system exactly in a compact subset of the state space. The number of sub-models is directly related to the number of nonlinear terms. For each nonlinear term, two sub-models are obtained such that for $k$ nonlinear terms, the global model is composed of $h=2^{k}$ sub-models. Therefore, the bigger is the number of nonlinear terms, the bigger becomes the conservatism of the global convex system and the computational burden of both analysis and synthesis.

The TS approach was adopted rapidly by the control community and was applied to state estimation [7], control [8], fault detection [7], descriptor systems [9], state observers [10], waste-water treatment plants [11], bioreactors [12], process industry [13,14], mechatronics [15,16], aeronautics $[17,18]$ and automotive $[19,20]$, among others. Comprehensive material about the topic can be found in Refs. [8,21-23] and the references therein. On the other hand, another school of thought named these approaches as quasi-LPV (qLPV) in order to differentiate fuzzy approaches from model-based approaches. Nonetheless, models obtained by means of the sector nonlinearity approach are not fuzzy, since the weighting functions are completely deterministic, as detailed in Ref. [24]. Literature on qLPV systems can be found in Refs. [25-33], just to mention a few.

It is clear that LPV and TS systems have been developed independently but recently some works have started discussing about the analogies between these paradigms [23,34,35]. For this reason, we find it appropriate to consider a terminology that includes both schools of thought and in this review we propose to denote both LPV and TS systems as convex systems. The idea of unifying these two paradigms under a single name is not new, as it was originally proposed in Ref. [36] and retaken in Refs. [37-40]. Nonetheless, in spite of the success of these paradigms, there is no literature review that allows tasting all the flavors offered by the vastness of convex approaches. Therefore, in this paper, three main aspects of convex systems are reviewed: control, observation and safety. The objective is to help the reader to locate themselves in the area of convex systems by learning about the main used techniques. It is worth highlighting that, although real-life applications of the reviewed methods are discussed whenever appropriate, the level of detail is kept low, since the main focus of this review is theoretical. The reader interested in a more extensive survey of experimental applications and validations based on high-fidelity simulations is referred to the excellent work in Ref. [41] and the references therein. 
The overall structure of this review is provided in Figure 1.

\section{INTRODUCTION}

2. CONTROL OF CONVEX SYSTEMS: it is dedicated to discuss advances and control techniques for convex systems

2.1 Convex state-feedback control

2.2 Convex output-feedback control

2.3 Convex tracking controller

2.4 Model predictive control fo convex systems

2.5 Final comments on control of convex systems

3. OBSERVATION OF CONVEX SYSTEMS: it is dedicated to observers

3.1 Convex observers

3.2 Robust observers

3.3 Proportional-integral observers

3.4 Descriptor observers

4. SAFETY IN CONVEX SYSTEMS: it is dedicated to fault diagnosis and fault tolerant control of convex systems

4.1 Residual generation for fault detection

4.2 Unknown input observers-based fault isolation

4.3 Observer-based fault estimation

4.4 Multiple model adaptive estimators

4.5 Sliding mode fault tolerant control

4.6 Fault tolerant control based on controller reconfiguration

4.7 Fault-hiding via virtual actuators and sensors

\section{CONCLUSIONS}

Figure 1. Structure of the review. 
Notation: The notation used in this article is quite standard. $\mathbb{R}^{m \times n}$ denotes the set of all matrices with $m$ rows and $n$ columns. If a square matrix $A \in \mathbb{R}^{n \times n}$ is symmetric, this fact will be denoted by $A \in \mathbb{S}^{n}$. Given a matrix $A \in \mathbb{S}^{n}, A \succ 0(A \prec 0)$ denotes positive (negative) definiteness, that is, that all its eigenvalues are positive (negative). Similarly, $A \succeq 0$ ( $A \preceq 0$ ) denotes positive (negative) semi-definiteness. For a matrix $A \in \mathbb{R}^{m \times n}, A^{T}$ and $A^{\dagger}$ denote its transpose and pseudo-inverse, respectively. If $A \in \mathbb{R}^{n \times n}$ is non-singular, $A^{-1}$ will denote its inverse. The symbol $*$ denotes the transposed element in a symmetric position of a matrix. Finally, $\operatorname{He}\{A\}$ is used as a shorthand notation for $A+A^{T}$.

\section{Control of Convex Systems}

Convex systems can arise from three possible interpretations [42]: (i) they can be seen as linear systems subject to uncertainties for which the synthesis of a controller must be approached from a robust control perspective; (ii) they can be seen as a family of parameter varying systems, for which the instantaneous value of the varying parameters can be injected directly in the control structure, leading to a gain scheduled control [43,44]; and (iii) the two previous situations can be combined, as suggested by Ref. [45], where a double-layer polytopic framework was considered to this end.

In the last years, significant progress has been made in the control of convex systems. For example, in the presence of uncertainties or disturbances, LPV robust control techniques have shown to provide better performance than robust LTI controllers [46,47]. Indeed, many linear matrix inequality (LMI)-based solutions for LTI systems have been extended to LPV systems, for example, an LPV stabilizing controller was proposed for an arm-driven inverted pendulum in Ref. [48] and was shown to outperform classical robust control techniques, such as $H_{\infty}$ and $\mu$-synthesis. However, the method in Ref. [48] does not guarantee that the closed-loop system exhibits a robust performance. To handle this problem, a parametrized LPV $H_{\infty}$ control was presented in Ref. [49], which showed good performance when applied to a turbofan jet engine. Other $H_{\infty}$ controllers for systems affected by time-varying parametric uncertainties can be consulted in Refs. [50,51]. In order to improve the performance of $H_{\infty}$ controllers, a switching controller designed with multiple Lyapunov functions was proposed by Ref. [52]. Similarly, an LPV control for switched systems with slow-varying parameters was proposed for an F-16 aircraft model in Ref. [53] by adopting the blending method developed by Ref. [54], which achieves the separation of the entire parameter set into overlapped subsets, such that the overall LPV controller can be blended over the entire region by means of regional controllers. In spite of the good achieved performance, the method is applicable only under the assumption that the scheduling parameters can be measured on-line, which is often difficult to satisfy in practice. To solve this problem, a robust compensator which considers prior and non-real-time knowledge of the varying parameters was proposed by Ref. [55] for stable polytopic LPV plants. Robust convex controllers have been also proposed in the context of networked nonlinear systems $[56,57]$ where the communication channel is affected by package dropouts intermittently.

\subsection{Convex State-Feedback Control}

The first convex developments were proposed in Ref. [58] and subsequent papers [2,44,59]. The main difference with respect to the robust control theory is that the varying parameters are assumed to be known and they can be used to schedule the time-varying controller gain. The most widely applied control approach is the state-feedback, for which a conceptual scheme is given in Figure 2. This approach computes the control law as follows:

$$
u(t)=K(\theta(t)) x(t)
$$

where $K(\theta(t)) \in \mathbb{R}^{n_{u} \times n_{x}}$ denotes the controller gain. It is the simplest control law that can be considered but its implementation requires knowing the full state of the system. Combining (1) and (3), the closed-loop system is described by the following autonomous convex system: 


$$
\dot{x}(t)=[A(\theta(t))+B(\theta(t)) K(\theta(t))] x(t)
$$

Hence, by using the Lyapunov candidate function $V(x(t))=x^{T}(t) P x(t)>0$, with $P \in \mathbb{S}^{n_{x}}$ and requiring $\dot{V}(x(t))<0$, the so-called quadratic stability condition is obtained, as follows:

$$
\operatorname{He}\{P A(\theta)+P B(\theta) K(\theta)\} \prec 0 \quad \forall \theta \in \Theta
$$

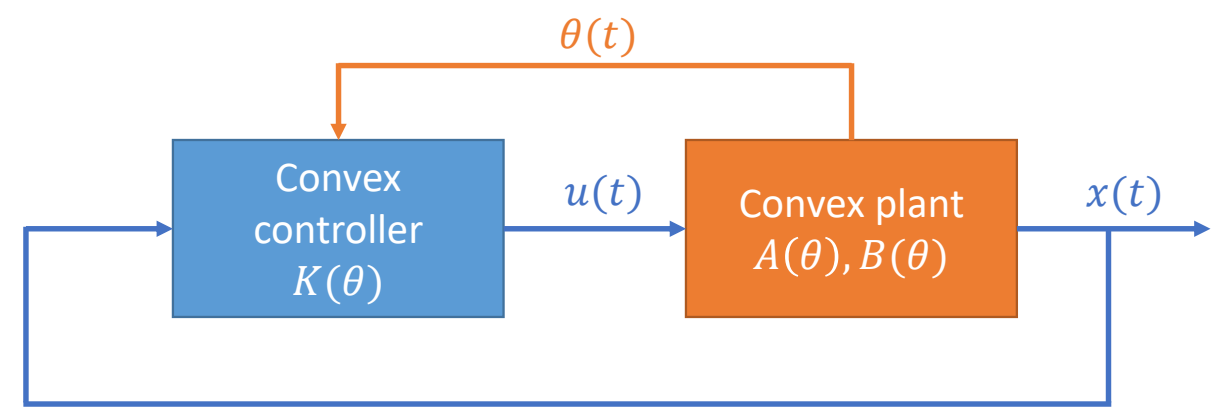

Figure 2. Conceptual scheme of convex control.

Equation (5) is a bilinear matrix inequality (BMI) as the unknown variables $K(\theta)$ and $P$ appear in the same product of matrices $P B(\theta) K(\theta)$. However, it is possible to transform (5) into an LMI by preand post-multipliying (5) by $Q=P^{-1}$, thus obtaining [60] (similarity transformations do not change the eigenvalues of a matrix, hence its positive/negative definiteness):

$$
\operatorname{He}\{Q P A(\theta) Q+Q P B(\theta) K(\theta) Q\} \prec 0 \quad \forall \theta \in \Theta
$$

Note that in this case $P Q=(P Q)^{T}=I$ and therefore the following is obtained:

$$
\operatorname{He}\{A(\theta) Q+B(\theta) K(\theta) Q\} \prec 0 \quad \forall \theta \in \Theta
$$

Finally, the quadratic term is eliminated by using the change of variables $\Gamma(\theta)=K(\theta) Q$, so that (7) becomes:

$$
\operatorname{He}\{A(\theta) Q+B(\theta) \Gamma(\theta)\} \prec 0 \quad \forall \theta \in \Theta
$$

which is in an LMI form. It is important to mention that, in the case that multiple specifications are desired, the above change of variables introduces some conservatism, since it forces to use the same Lyapunov matrix $Q$ for all specifications, whereas using different matrices for different specifications would lead to better performance. However, using LMIs instead of BMIs is convenient due to the computational efficiency of available LMI solvers, whereas BMIs are non-convex, so that there is no guarantee of obtaining a global minimum. Equation (8) represents an infinite number of constraints, therefore it presents a computational problem. Unfortunately, the direct application of a polytopic approach is not straightforward. One could rewrite (8) as:

$$
\mathcal{M}_{i j}:=\operatorname{He}\left\{A_{i} Q+B_{j} \Gamma_{i}\right\} \prec 0 \quad \forall i, j=1, \ldots, h
$$

and achieve stabilization by using $u(t)=K(\theta(t)) x(t)$, with the feedback controller gain obtained as $K(\theta(t))=\Gamma(\theta(t)) Q^{-1}$, where $\Gamma(\theta(t))=\sum_{i=1}^{h} \rho_{i}(\theta(t)) \Gamma_{i}$ and $\rho_{i}(\theta(t))$ denotes the coefficients of the following polytopic decomposition: 


$$
\left[\begin{array}{c}
A(\theta(t)) \\
B(\theta(t))
\end{array}\right]=\sum_{i=1}^{h} \rho_{i}(\theta(t))\left[\begin{array}{c}
A_{i} \\
B_{i}
\end{array}\right], \quad \sum_{i=1}^{h} \rho_{i}(\theta(t))=1, \quad \rho_{i}(\theta(t)) \geq 0 \quad \forall \theta \in \Theta
$$

However, this solution has the drawback that a vertex gain $K_{i}$ must be robust with respect to all possible values of $B(\theta(t))$, which corresponds to a high degree of conservatism. For this reason, alternative solutions can be found in the literature, such as that proposed by Ref. [61] which consists in pre-filtering the control input $u(t)$. The combination of the filter and the system (1) leads to a convex system with constant input matrix since $B(\theta(t))$ appears embedded into the state matrix of the augmented system. However, it must be mentioned that some recent work has questioned the advantages of the pre-filter against using directly the LMIs (9) for the controller design [62,63].

Other alternative solutions aim at relaxing (9), although usually the requirement of low conservatism is associated with an increase in the computational load. Among these solutions, it is worth mentioning the conditions proposed by Ref. [64], who presented a fuzzy control application of the Polya's theorems on positive forms in the standard simplex. The result is a set of sufficient conditions to prove the positiveness of double sums, which are progressively less conservative as a complexity parameter $n$ increases. These conditions are asymptotically exact, that is, necessary and sufficient when $n$ tends to infinity. Other conditions are those obtained by generating partitions of the polytope through the triangulation method [65], which allows to obtain a family of sufficient conditions for positivity/negativity of double sums and, in parallel, another family of necessary conditions, which become asymptotically exact by decreasing the size of the partitions. In addition, one can recall the conditions proposed by Ref. [66], that allow to relax the conditions of double polytopic sum to take into account, for example, the existence of gaps in the set $\Theta$. Nonetheless, the most popular relaxation is the one proposed by Tuan et al. [67], which considers that an LMI in the form of (9) is equivalent to:

$$
\begin{array}{ll}
\mathcal{M}_{i j} \prec 0 & i \in[1,2, \ldots, h] \\
\frac{2}{h-1} \mathcal{M}_{i i}+\mathcal{M}_{i j}+\mathcal{M}_{j i} \preceq 0 & 1 \leq i \neq j \leq h
\end{array}
$$

which reduces the conservatism and increases the applicability of the controller.

For convex qLPV and TS systems, Equations (9) and (11) are also known as parallel distributed compensation (PDC) [68]. In this case, the feedback controller and the convex system share the same weighting functions and the LMI conditions are obtained with the direct Lyapunov method. However, the more local models the convex representation has, the greater is the conservatism of the LMI solution. This fact follows from the necessity of finding a feasible solution that employs a common matrix $P$ for all the local models. A possible strategy to reduce the conservatism is to consider nonquadratic Lyapunov functions (NQLFs) as done, for example, in Refs. [69-72]. The solution obtained through NQLFs, which is also known as non-PDC [73,74], reduces considerably the conservatism and maintains the same weighting functions for both the convex model and the controller. However, non-PDC controllers are harder to design than PDC controllers, since the weighting functions involve time derivatives of the NLQF, leading to local results [75]. This problem does not arise in convex systems dependent on exogenous time-varying parameters, because the NLQLF would not involve time derivatives of the states, hence global solutions can be obtained for this case [72,76-78].

\subsection{Convex Output-Feedback Control}

A variant of the state-feedback control strategy previously described consists in using directly the output $y(t)$ for feedback, which is easier to implement in cases where the state is unavailable for measurement. Nevertheless, some conditions have to be ensured to make it possible to synthesize these controllers, by means of approaches initially developed in the robust context and later extended to the LPV framework [79-82]. 
The next result allows the quadratic stabilization of a convex system of the form (1)-(2) using a convex dynamic output-feedback controller defined as:

$$
\begin{aligned}
& \dot{x}_{K}(t)=A_{K}(\theta(t)) x_{K}(t)+B_{K}(\theta(t)) y(t) \\
& u(t)=C_{K}(\theta(t)) x_{K}(t)+D_{K}(\theta(t)) y(t)
\end{aligned}
$$

where $x_{K}(t) \in \mathbb{R}^{n_{x}}$ is the internal state of the controller and $A_{K}(\theta(t)), B_{K}(\theta(t)), C_{K}(\theta(t)), D_{K}(\theta(t))$ are matrix-valued functions, such that the closed-loop system obtained by the connection of (1)-(2) and (13)-(14) is stable. In particular, the closed-loop system is described by the following autonomous convex system:

$$
\left[\begin{array}{c}
\dot{x}(t) \\
\dot{x}_{K}(t)
\end{array}\right]=\left[\begin{array}{cc}
A(\theta(t))+B(\theta(t)) D_{K}(\theta(t)) C(\theta(t)) & B(\theta(t)) C_{K}(\theta(t)) \\
B_{K}(\theta(t)) C(\theta(t)) & A_{K}(\theta(t))
\end{array}\right]\left[\begin{array}{c}
x(t) \\
x_{K}(t)
\end{array}\right]
$$

Due to the presence of $C(\theta(t))$ post-multiplying $B_{K}(\theta(t))$ and $D_{K}(\theta(t))$ in (15), the procedure to obtain LMIs for design of the controller's matrices is somehow more complex. The system (1)-(2) is quadratically stabilizable using the convex controller (13)-(14) if there exist a positive definite matrix $P \in \mathbb{S}^{2 n_{x}}$ such that $A_{c l}(\theta) P+P A_{c l}(\theta) \prec 0, \forall \theta \in \Theta$, where $A_{c l}(\theta)$ is the state matrix of the autonomous system (15). Following Refs. [83,84], this condition is achieved if and only if there exist matrices $Q \succ 0$ and $S \succ 0$ and matrix-valued functions $\hat{C}_{K}(\theta)$ and $\hat{B}_{K}(\theta)$ such that the following holds $\forall \theta \in \Theta$ :

$$
\begin{aligned}
\operatorname{He}\left\{A(\theta) Q+B(\theta) \hat{C}_{K}(\theta)\right\} & \prec 0 \\
\operatorname{He}\left\{S A(\theta)+\hat{B}_{K}(\theta) C(\theta)\right\} & \prec 0
\end{aligned}
$$

A possible methodology to obtain the controller's matrices after solving (16)-(17) is described hereafter [85]. If (16)-(17) and the following condition hold:

$$
\left(\begin{array}{cc}
Q & I \\
I & S
\end{array}\right) \succ 0
$$

then, by letting $M, N$ be non-singular matrices such that $M N^{T}=I-S Q$ and choosing $D_{K}(\theta(t))=0$, the controller's matrices $A_{K}(\theta(t)), B_{K}(\theta(t))$ and $C_{K}(\theta(t))$ can be computed as follows:

$$
\begin{aligned}
B_{K}(\theta(t))= & M^{-1}\left[\hat{B}_{K}(\theta(t))-S B(\theta(t)) D_{K}(\theta(t))\right] \\
C_{K}(\theta(t))= & {\left[\hat{C}_{K}(\theta(t))-D_{K}(\theta(t)) C(\theta(t)) Q\right] N^{-T} } \\
A_{K}(\theta(t))= & M^{-1}\left[\hat{A}_{K}(\theta(t))-S B(\theta(t)) C_{K}(\theta(t)) N^{T}-M B_{K}(\theta(t)) C(\theta(t)) Q\right. \\
& \left.-S\left(A(\theta(t))+B(\theta(t)) D_{K}(\theta(t)) C(\theta(t))\right) Q\right] N^{-T}
\end{aligned}
$$

On the other hand, if (18) does not hold, then the matrices have to be adjusted using $Q_{\lambda}=\lambda Q$, $S_{\lambda}=\lambda S, \hat{B}_{K \lambda}(\theta(t))=\lambda \hat{B}_{K}(\theta(t))$ and $\hat{C}_{K \lambda}(\theta(t))=\lambda \hat{C}_{K}(\theta(t))$, where $\lambda>1$, until (18) holds with these new variables and the controller's matrices can be computed.

Equation (18) guarantees the existence of the invertible matrices $M$ and $N$ used for controller computation. In the same way, the conditions to perform $H_{\infty}$ control, control with guaranteed cost or to achieve other specifications can be obtained. Note that double polytopic sums appear due to the terms $B(\theta) \hat{C}_{K}(\theta)$ and $\hat{B}_{K}(\theta) C(\theta)$ in (16)-(17). If the controller is restricted to the case where $\hat{B}_{K}(\theta)$ and $\hat{C}_{K}(\theta)$ are constant, then the LMIs (16)-(17) can be reduced to a finite number of conditions easily, otherwise the discussion provided in the previous section about possible relaxations would apply with slight modifications. It is worth remarking that in convex systems in which $\theta(t)$ depends on 
unmeasured states, the analysis and design of the output feedback control become more complicated, see for example, Ref. [86].

\subsection{Convex Tracking Controller}

Consider a convex system subject to unknown inputs ans sensor noise, described by (for the sake of simplicity, the output matrix is assumed to be constant):

$$
\begin{aligned}
& \dot{x}(t)=A(\theta(t)) x(t)+B(\theta(t)) u(t)+R(\theta(t)) d(t) \\
& y(t)=C x(t)+G d(t)
\end{aligned}
$$

where $d(t) \in \mathbb{R}^{n_{d}}$ is the disturbance vector comprising both unknown inputs and noise and $R(\theta(t))$ and $G$ are matrices of appropriate dimensions. As illustrated in Figure 3, a convex tracking controller can be considered for this system, with control law:

$$
u(t)=K_{1}(\theta(t)) x(t)+K_{2}(\theta(t)) \epsilon(t)=\mathcal{K}(\theta(t))\left[\begin{array}{ll}
x(t) & \epsilon(t)
\end{array}\right]^{T}
$$

where $K_{1}(\theta(t))$ and $K_{2}(\theta(t))$ are the gains to be designed and $\epsilon(t)$ is the integration error, added to compensate steady-state errors and reach the desired output $w(t)$ :

$$
\dot{\epsilon}(t)=w(t)-y(t)=w(t)-C x(t)-G d(t)
$$

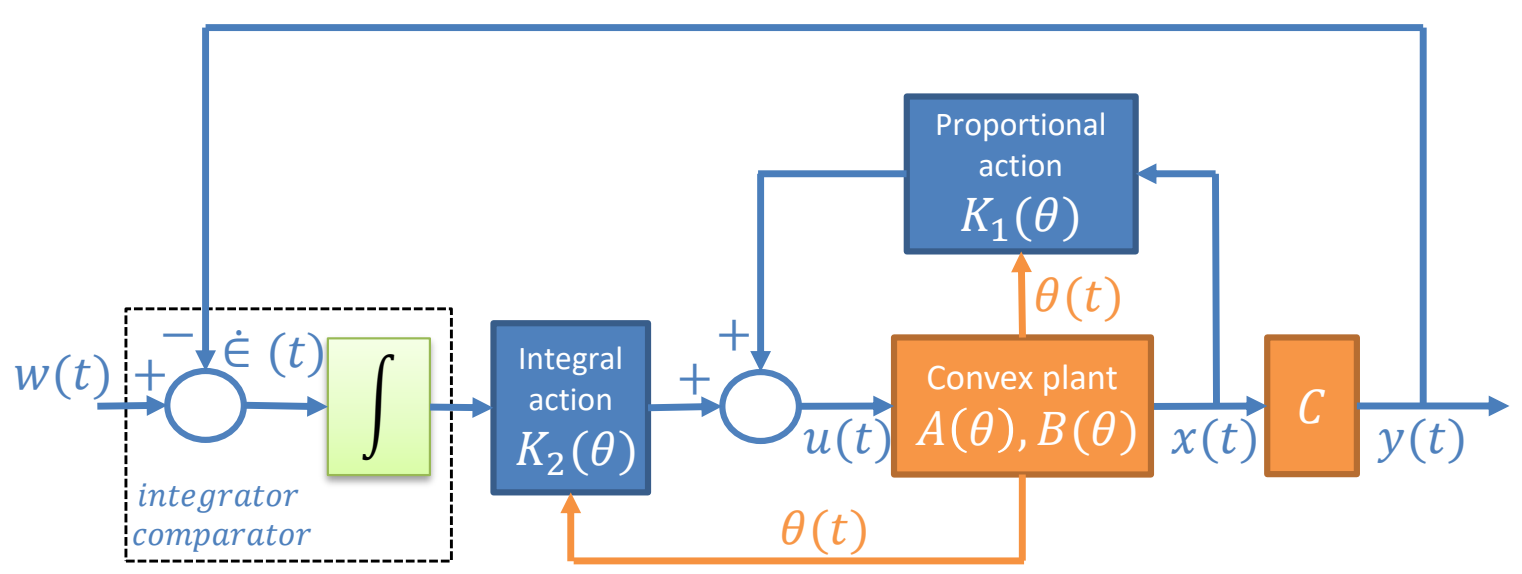

Figure 3. Convex tracking controller scheme.

The system augmented with the integrator can be rewritten in a compact form by introducing the augmented state vector $x_{c}(t)=\left[\begin{array}{ll}x^{T}(t) & \epsilon^{T}(t)\end{array}\right]^{T}$ :

$$
\dot{x}_{c}(t)=\bar{A}_{c}(\theta(t)) x_{c}(t)+\bar{B}_{c}(\theta(t)) u(t)+\bar{R}_{c}(\theta(t)) d(t)+\bar{B}_{w} w(t)
$$

with:

$$
\bar{A}_{c}(\theta(t))=\left[\begin{array}{cc}
A(\theta(t)) & 0 \\
-C & 0
\end{array}\right] \quad \bar{B}_{c}(\theta(t))=\left[\begin{array}{c}
B(\theta(t)) \\
0
\end{array}\right] \quad \bar{B}_{w}=\left[\begin{array}{l}
0 \\
I
\end{array}\right] \quad \bar{R}_{c}(\theta(t))=\left[\begin{array}{c}
R(\theta(t)) \\
-G
\end{array}\right]
$$

The closed loop system has the form:

$$
\dot{x}_{c}(t)=\sum_{i=1}^{h} \rho_{i}(\theta(t)) \sum_{j=1}^{h} \rho_{j}(\theta(t))\left[\left(\bar{A}_{c i}-\bar{B}_{c i} \mathcal{K}_{j}\right) x_{c}(t)+\bar{B}_{R w i} \bar{a}_{w}(t)\right]
$$


with:

$$
\bar{B}_{R w i}=\left[\begin{array}{ll}
\bar{R}_{i} & \bar{B}_{w}
\end{array}\right], \bar{d}_{w}(t)=\left[\begin{array}{ll}
d(t) & w(t)
\end{array}\right]^{T}
$$

Sufficient conditions for the existence of the controller are given in Ref. [35] and presented hereafter. Consider the system (22)-(23), the feedback control law defined by (24), the integrator, and let the attenuation level be given by $\gamma_{c}>0$. The closed loop system error (25) is globally stable with $H_{\infty}$ performance if $\left\|x_{c}(t)\right\|_{2}^{2}<\gamma_{c}^{2}\left\|\bar{d}_{\omega}(t)\right\|_{2}^{2}$ and if there exists a matrix $X \succ 0$ such that $\forall i, j \in[1,2, \ldots, h]$, the following holds:

$$
\left[\begin{array}{cc}
\operatorname{He}\left(X \bar{A}_{c i}^{T}+\Xi_{j}^{T} \bar{B}_{c i}^{T}\right)+\bar{B}_{R w i} \bar{B}_{R w i}^{T} & X \\
* & -\gamma_{c}^{2} I
\end{array}\right] \prec 0
$$

Then, the controller gain matrices are computed by $\mathcal{K}_{j}=\left[\begin{array}{ll}K_{1 j} & K_{2 j}\end{array}\right]=X^{-1} \Xi_{j}$.

This is possible because if we consider the $\mathcal{L}_{2}$-gain from $\bar{d}_{\omega}(t)$ to $x_{c}(t)$ such that:

$$
J_{x_{c} d}=\dot{V}(t)+x_{c}^{T}(t) x_{c}(t)-\gamma_{c}^{2} \bar{d}_{\omega}^{T}(t) \bar{d}_{\omega}(t)<0
$$

where $V(t)$ is a quadratic Lyapunov function, the LMI (30) is obtained after solving the performance criteria (31). Complete procedures are described in detail in Ref. [35].

An alternative approach is to use a reference model as originally proposed by Ref. [87] and later applied by Refs. [26,88], which has the advantage that the tracking error is described by an autonomous system, so its convergence to zero can be guaranteed even without the use of an integrator.

\subsection{Model Predictive Control for Convex Systems}

Model predictive control (MPC) is a control strategy that is based on the use of a mathematical model to predict the system's behavior in a future time window and then finds the optimal input sequence by minimizing a cost function $[89,90]$. Only the first calculated input is applied to the system and the remaining are discarded, repeating this prediction-optimization process at every sample. This control technique is popular because it can take into account systematically complex dynamics, as well as physical and process quality constraints [91].

Consider the discrete-time convex system:

$$
x(k+1)=A(\theta(k)) x(k)+B(\theta(k)) u(k)
$$

where $A(\theta(k))=\sum_{j=1}^{l} \theta_{j}(k) A_{j}$ and $B(\theta(k))=\sum_{j=1}^{l} \theta_{j}(k) B_{j}$. Therefore, $\theta(k)$ belongs to a convex polytope $\Theta$ defined by the values $\theta_{j}(k)$ such that $\sum_{j=1}^{l} \theta_{j}(k)=1$, with, $0 \leq \theta_{j}(k) \leq 1$. On the other hand, when $\theta(k)$ varies in the polytope $\Theta$, the system matrices vary in the polytope $\Omega$ defined as follows:

$$
[A(\theta(k)), B(\theta(k))] \in \Omega=\operatorname{Co}\left\{\left[A_{1}, B_{1}\right],\left[A_{2}, B_{2}\right], \ldots,\left[A_{l}, B_{l}\right]\right\}
$$

where $\left[A_{i}, B_{i}\right]$ are the vertex matrices obtained when $\theta_{i}=1$ and $\theta_{j}=0$ for $j \neq i$. Hereafter, for illustrative purposes, it is assumed that there is no model uncertainty and that both the scheduling variable $\theta(k)$ and the state $x(k)$ are known at time $k$. However, the future evolution of the model is uncertain since future values of $\theta(k)$ are unknown.

Let us define the following quadratic cost function:

$$
J(k)=\underbrace{x(k \mid k)^{T} Q x(k \mid k)+u(k \mid k)^{T} R u(k \mid k)}_{J_{0}(k)}+\underbrace{\sum_{i=1}^{\infty} x(k+i \mid k)^{T} Q x(k+i \mid k)+u(k+i \mid k)^{T} R u(k+i \mid k)}_{J_{1}(k)}
$$


where $Q, R$ are weighting matrices with appropriate dimensions and the notation $x(k+i \mid k)$ represents the predicted value for the state variable $x$ at the future sample $k+i$ calculated at sample $k$. Hence, $J_{0}(k)$ correspond to the first prediction step and $J_{1}(k)$ correspond to the remaining of the prediction.

Let $U(k)$ be the sequence of inputs computed at sample $k$, that is, $U(k)=\left[u(k \mid k), U_{1}(k)\right]=$ $[u(k \mid k), u(k+1 \mid k), \ldots]$. Then, the optimal control sequence is obtained by minimizing the maximum value that the cost function (34) can take for all the possible future trajectories of the parameter $\theta(k)$, that is,

$$
U^{*}(k)=\min _{U(k)} \max _{[A(\theta(k+i)), B(\theta(k+i))] \in \Omega} J(k)
$$

where $*$ denotes optimality. The first element of $U^{*}(k)$, that is, $u^{*}(k \mid k)$, is applied to the system, while the remaining of the sequence $U_{1}^{*}(k)$ can be proven to be equivalent to a state feedback control law whose gain does not depend on the instantaneous value of $\theta(k)$ (see Ref. [92] for further details), that is,

$$
U_{1}^{*}(k)=\{u(k+i \mid k)=K(k) x(k+i \mid k), i \geq 1\}
$$

Following Ref. [92], instead of solving (35), an upper bound for the term $J_{1}(k)$ can be defined, as follows:

$$
\max _{[A(\theta(k+i)), B(\theta(k+i))] \in \Omega, i \geq 0} \quad J_{1}(k) \leq V(x(k+1 \mid k))=x(k+1 \mid k)^{T} P x(k+1 \mid k) \quad P(k) \succ 0 .
$$

Then, an upper bound of the worst case of $J(k)$ is minimized instead of (35), as follows:

$$
U^{*}(k)=\min _{u(k \mid k), P(k)} x(k \mid k)^{T} Q x(k \mid k)^{T}+u(k \mid k)^{T} R u(k \mid k)^{T}+x(k+1 \mid k)^{T} P x(k+1 \mid k)
$$

The optimization problem (38) can be reformulated as the following minimization problem:

$$
\min _{\gamma, u(k \mid k), \tilde{Q}(k), Y(k)} \gamma
$$

subject to LMIs:

$$
\begin{aligned}
& {\left[\begin{array}{cccc}
1 & \hat{x}(k+1 \mid k)^{T} & \hat{x}(k \mid k)^{T} Q^{\frac{1}{2}} & u(k \mid k)^{T} R^{\frac{1}{2}} \\
\hat{x}(k+1 \mid k) & \tilde{Q}(k) & 0 & 0 \\
Q^{\frac{1}{2}} x(k \mid k) & 0 & \gamma I & 0 \\
R^{\frac{1}{2}} u(k \mid k) & 0 & 0 & \gamma I
\end{array}\right] \succeq 0} \\
& {\left[\begin{array}{cccc}
\tilde{Q}(k) & \tilde{\Gamma}_{j}(k)^{T} & \tilde{Q}(k) Q^{\frac{1}{2}} & \gamma(k)^{T} R^{\frac{1}{2}} \\
\tilde{\Gamma}_{j}(k) & \tilde{Q}(k) & 0 & 0 \\
Q^{\frac{1}{2}} \tilde{Q}(k) & 0 & \gamma I & 0 \\
R^{\frac{1}{2}} Y(k) & 0 & 0 & \gamma I
\end{array}\right] \succeq 0 \quad \forall j=1, \ldots, l}
\end{aligned}
$$

with $\hat{x}(k+1 \mid k)=[A(\theta(k)) x(k \mid k)+B(\theta(k)) u(k \mid k)], \tilde{\Gamma}_{j}(k)=A_{j} \tilde{Q}(k)+B_{j} Y(k)$ and $\tilde{Q}(k) \succeq 0$. The gain in (36) is computed as $K(k)=Y(k) \tilde{Q}^{-1}(k)$, which guarantees that the state evolves in an ellipsoidal invariant set.

Considering the system output as $y(k)=C x(k)$, the cost function (34) may be subject to constraints [93]:

$$
\begin{array}{r}
|u(k \mid k)| \leq u_{\max } \\
\|\left. C[A(\theta(k)) x(k \mid k)+B(\theta(k)) u(k \mid k)]\right|_{2} \leq y_{\max }
\end{array}
$$


Constraints on the inputs are satisfied if there exists a matrix $X \succeq 0$ such that:

$$
\left[\begin{array}{cc}
X & Y \\
Y^{T} & \tilde{Q}
\end{array}\right] \succeq 0 \quad \text { with } \quad X_{i i} \leq u_{\max }^{2}
$$

In a similar way, the constraints on the outputs are equivalent to the LMI:

$$
\left[\begin{array}{cc}
\tilde{Q} & {\left[A_{j} \tilde{Q}+B_{j} Y\right]^{T} C^{T}} \\
C\left[A_{j} \tilde{Q}+B_{j} Y\right] & y_{\max }^{2}
\end{array}\right] \succeq 0 \quad j=1, \ldots, l
$$

The constrained MPC algorithm with control law (36) can be obtained by solving the optimization problem (39) subject to the LMIs (40), (41), (44), (45) and constraints (42) and (43). However, although this algorithm does not impose $u(k \mid k)$ and $y(k+1 \mid k)$ to invariant ellipsoid constraints, still includes constraints on all future inputs and outputs. A method to improve the conservatism is to relax the future constraints (44) and (45) and bound only $u(k \mid k)$ and $y(k+1 \mid k)$ [93]. To guarantee stability an additional constraint that ensures that the cost function decreases monotonously $(\phi(k)<\phi(k-1)$ with $\left.\phi(k)=x(k \mid k)^{T} Q x(k \mid k)^{T}+u(k \mid k)^{T} R u(k \mid k)^{T}+x(k+1 \mid k)^{T} P x(k+1 \mid k)\right)$ has to be included in the optimization:

$$
\min _{\gamma, u(k \mid k), \hat{Q}(k), Y(k)} \gamma
$$

subject to LMIs:

$$
\begin{aligned}
& {\left[\begin{array}{cccc}
\gamma & \hat{x}(k+1 \mid k)^{T} & x(k \mid k)^{T} Q^{\frac{1}{2}} & u(k \mid k)^{T} R^{\frac{1}{2}} \\
\hat{x}(k+1 \mid k) & \hat{Q}(k) & 0 & 0 \\
Q^{\frac{1}{2}} x(k \mid k) & 0 & I & 0 \\
R^{\frac{1}{2}} u(k \mid k) & 0 & 0 & I
\end{array}\right] \succeq 0} \\
& {\left[\begin{array}{cccc}
\phi(k-1) & \hat{\Gamma}_{j}(k)^{T} & \hat{Q}(k) Q^{\frac{1}{2}} & Y(k)^{T} R^{\frac{1}{2}} \\
\hat{\Gamma}_{j}(k) & \hat{Q}(k) & 0 & 0 \\
Q^{\frac{1}{2}} \hat{Q}(k) & 0 & I & 0 \\
R^{\frac{1}{2}} Y(k) & 0 & 0 & I
\end{array}\right] \succeq 0 \quad \forall j=1, \ldots, l} \\
& {\left[\begin{array}{c}
u(k \mid k)-u_{\max } \\
-u_{\max }-u(k \mid k)
\end{array}\right] \leq 0} \\
& {\left[\begin{array}{c}
C[A(\theta(k)) x(k \mid k)+B(\theta(k)) u(k \mid k)]-y_{\max } \\
-y_{\max }-C[A(\theta(k)) x(k \mid k)+B(\theta(k)) u(k \mid k)]
\end{array}\right] \leq 0}
\end{aligned}
$$

with $\hat{\Gamma}_{j}(k)=A_{j} \hat{Q}(k)+B_{j} Y(k)$ and $\hat{Q}(k) \succeq 0$. The gain of the control law (36) is computed as $K(k)=Y(k) \hat{Q}^{-1}(k)$. To initialize the algorithm, in $k=0$, the Lyapunov constraint $\phi(k)<\phi(k-1)$ is not taken into account. The resulting control strategy, which is depicted in Figure 4, provides guaranteed closed-loop stability provided that a feasible solution has been found. A parameter dependant feedback law instead of (36) can also be considered as in Ref. [93]. 


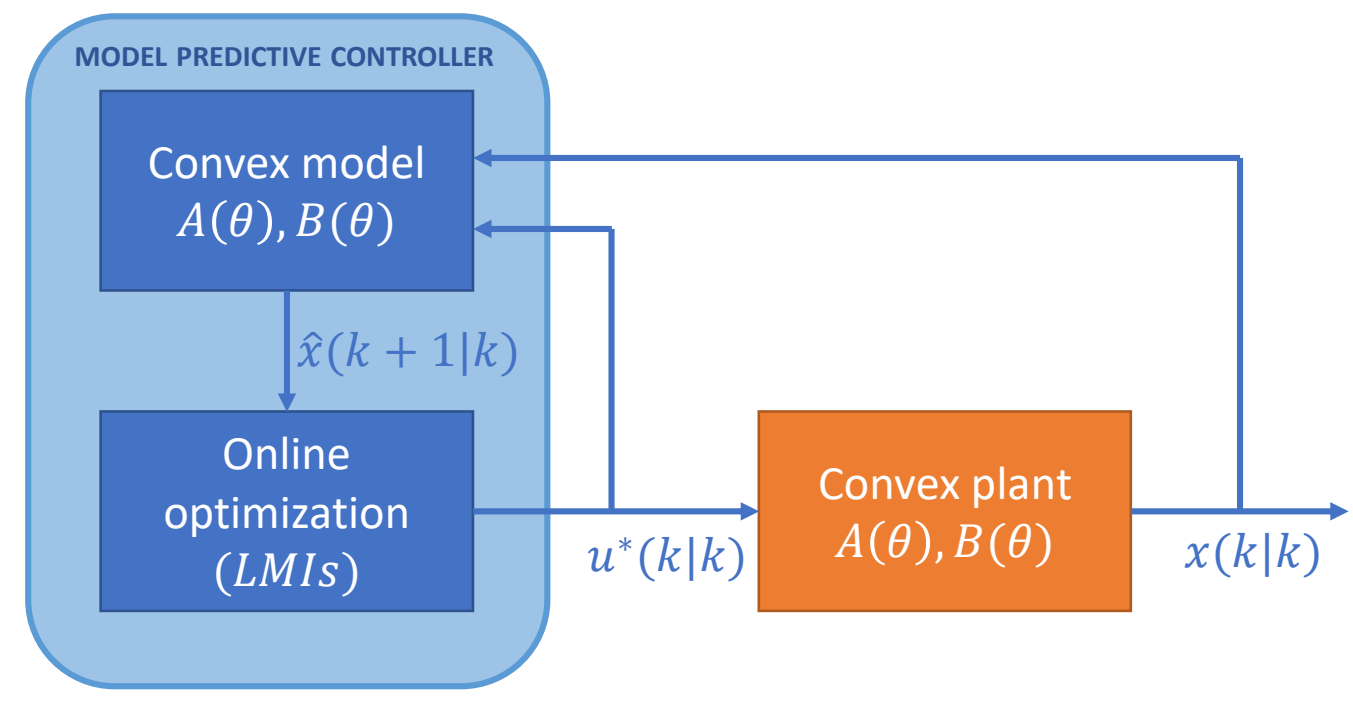

Figure 4. Convex model predictive control scheme.

Most of the MPC strategies for convex systems are based on the algorithm proposed by Ref. [92] since it stabilises robustly an LPV system for all possible parameter variations. However, such algorithm was not thought for application to LPV systems and therefore it suffers from being conservative and computationally demanding. The strategies proposed by Refs. [93,94], which consider bounds in the parameter variations, show less conservatism and a decreased computational load when compared to Ref. [92]. A modification of Ref. [93] that involves updating the polytope $\Omega$ while keeping it defined by the least possible number of vertices has been presented in Ref. [95]. This innovation is motivated by the fact that the fewer vertices are used to describe $\Omega$, the less likely it is that infeasibility problems could occur. In Ref. [96], an extension to nonlinear systems has been presented, where a linearized model is obtained from the nonlinear model at each sample and then an LPV model that varies in a politope $\Omega$ is used for obtaining the state prediction. Other existing approaches are focused on the use of Lyapunov functions that depend on $\theta(k)$ that enlarge the feasible region $[97,98]$. In line with this work, an algorithm that uses closed-loop predictions with good achieved performance and low computational requirements was presented in Ref. [99]. More recently, Ref. [100] has presented a class of nonlinearly parameterized Lyapunov functions to achieve more efficient relaxed stability conditions. A robust MPC scheme for LPV systems where the varying parameters are assumed to be measured online and exploited for feedback has been derived in Ref. [101]. Explicit MPC for convex systems has been also proposed in order to avoid the need of online optimization [102,103]. In general, MPC for convex systems has been a topic that has received an intense interest by the research community in the last few years, for which the interested reader is referred to Refs. [104-107] and the references therein.

\subsection{Final Comments on Control of Convex Systems}

It is worth noting that what has been discussed in this section about the control of convex systems does not apply only to the problem of controller design for quadratic stabilization but also to the case of other specifications, such as $\mathcal{D}$-stabilization [108], $H_{\infty}$ control [109], control with guaranteed cost [110] and many more. The described methods can be adapted to deal with convex systems with piecewise constant parameters, which provide a unifying concept lying in between the robust and the gain-scheduled perspectives, including both as extremal cases [111].

On the other hand, there are some cases in which the direct application of the convex techniques described so far would not work, for example, due to the loss of controllability for some points of the design polytope, so that alternative strategies must be employed. For instance, consider the following simplified model of a unicycle mobile robot 


$$
\left[\begin{array}{c}
\dot{x}(t) \\
\dot{y}(t) \\
\dot{\alpha}(t)
\end{array}\right]=\left[\begin{array}{cc}
\cos (\alpha(t)) & 0 \\
\sin (\alpha(t)) & 0 \\
0 & 1
\end{array}\right]\left[\begin{array}{c}
v \\
w
\end{array}\right]
$$

where $x, y$ are the spacial 2D coordinates, $v$ and $w$ are the mobile robot translational and angular velocities, respectively and $\alpha$ denotes the orientation with respect to the fixed frame. If $\alpha \in[-\pi, \pi]$ were considered, one would get a non-controllable convex models in the vertices although the underlying nonlinear system is actually controllable. For example, the solution proposed in Ref. [88] was based on dividing the parameter space in regions and use a switched approach in order to avoid the above-mentioned singularities.

Another important theoretical point to be remarked is that the LMI-based assessment of stability (or some other goal) in convex systems arising from an underlying nonlinear system could mislead to believe that global stability (or performance) would hold for the original system. This fact is in general not true, as shown remarkably by Ref. [112] with a simple second order autonomous nonlinear system, that is, the well known Van der Pol equation. Fortunately, Ref. [112] also shows that it is possible to estimate the region of attraction for the nonlinear system, based on the Lyapunov function obtained for the convex system. This fact was further studied by Refs. [113-115] and was used by Ref. [34] to create a metric to compose different convex models obtained for the same nonlinear system.

Finally, it is worth mentioning that analysis and control problems for convex systems with delays have also attracted some recent interest $[116,117]$. These systems belong to the intersection of convex systems and time-delay systems, so they inherit the difficulties of each one. In particular, the stability analysis of these systems must be performed using tools such as Lyapunov-Razumikhin functions and Lyapunov-Krasovskii functionals, which increase the number of decision variables [118]. The interested reader is referred to the monograph [119] and the references therein.

\section{Observation of Convex Systems}

In many real-world applications there are some internal state variables that cannot be measured with the available sensors. Nevertheless, many control techniques are based on the assumption that the whole state is available, which is not always true. In practice, the available information concerns the input $u(t)$ and the output $y(t)$, rather than the state $x(t)$. In such case, the observability properties state that when the system is observable, the initial state can be determined and, therefore, the state trajectory can be reconstructed from input and output measurements, by means of the so-called state observer. State observers are dynamical systems that are designed to estimate asymptotically the state vector $x(t)$. Applications of convex observers can be found in UAVs [120], electric vehicles [121], networked systems [122], DC motors [123], wind turbines [124], riderless bicycles [125], to mention a few.

\subsection{Convex Observers}

The most common state observer is the one named after Luenberger, which for a convex systems has the following form [126] (see Figure 5):

$$
\begin{aligned}
& \dot{\hat{x}}(t)=A(\theta(t)) \hat{x}(t)+B(\theta(t)) u(t)+L(\theta(t))(y(t)-\hat{y}(t)) \\
& \hat{y}(t)=C \hat{x}(t)
\end{aligned}
$$

where $\hat{x}(t) \in \mathbb{R}^{n_{x}}$ denotes the state estimate, $\hat{y}(t) \in \mathbb{R}^{n_{y}}$ denotes the output estimate and the meaning of the remaining variables can be inferred from the previous section. The scheduled observer gains $L(\theta(t))$ are designed to guarantee closed-loop stability of the estimation error dynamics for all values 
of $\theta(t)$, such that the estimation error between the observer (52)-(53) and the system (1)-(2) converges towards zero. Let us define the estimation error as follows:

$$
e(t):=x(t)-\hat{x}(t)
$$

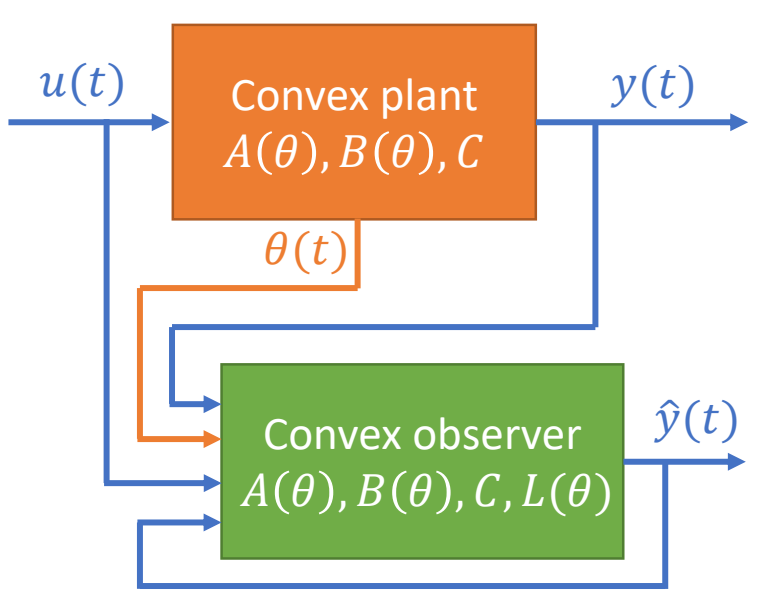

Figure 5. Convex state observer scheme.

Then, the estimation error dynamics is defined as:

$$
\dot{e}(t)=(A(\theta(t))-L(\theta(t) C)) e(t)
$$

The stability condition of the above differential equation can be obtained by means of LMI-based techniques, for example by considering the quadratic stability concept. In this case, one seeks the existence of a quadratic Lyapunov function $V(e(t))=e(t)^{T} P e(t) \geq 0, P \succ 0$, whose derivative over the error dynamics is given by:

$$
V(e(t))=\dot{e}(t)^{T} P e(t)+e(t)^{T} P \dot{e}(t)=e(t)^{T}(\operatorname{He}\{P A(\theta(t))-P L(\theta(t)) C\}) e(t)<0
$$

In order to eliminate the quadratic term, the change of variable $W(\theta(t)=P L(\theta(t)$ is considered, such that the following LMI is obtained:

$$
\operatorname{He}\{P A(\theta)-W(\theta) C\} \prec 0 \quad \forall \theta \in \Theta
$$

where the observer gain matrix can be computed later from its solution as $L(\theta(t))=P^{-1} W(\theta(t))$.

Furthermore, to improve the speed convergence of the state observer, a decay rate $\alpha<0$ can be added as requirement, by asking that:

$$
\dot{V}(e(t))+2 \alpha P<0
$$

which is also known in the literature as $\alpha$-stabilization. As a result, the LMI (56) is replaced by the following:

$$
\operatorname{He}\{P A(\theta)-W(\theta) C\}+2 \alpha P \prec 0 \quad \forall \theta \in \Theta
$$

It should be noticed that the stability of a state observer is guaranteed if the LMI (58) has a solution. Nevertheless, the approach described so far does not consider disturbances or measurement noise, which affect all physical systems. 


\subsection{Robust Observers}

Dynamical systems can be affected by external disturbances and measurement noise and, moreover, there exists always a mismatch between the real plant and its model used for control. These effects can lead to the loss of stability or performance if not taken into account appropriately. A control system that remains stable and with none (or little) performance loss despite the disturbances/noise is said to be robust. In other words, robustness means that the system remains stable and with almost the same performance even in the presence of disturbance, model mismatches or noise. For example, a wind turbine system must keep its efficiency even in the presence of air velocity changes. In contrast, an example of unwanted disturbance amplification is the Tacoma Narrows suspension bridge, where strong winds caused resonant oscillations of increasing magnitude in the bridge structure, which ultimately led to its destruction.

In particular, the robust state observer design problem is related to finding the observer gains such that it is always possible to estimate the real states within prescribed tolerances, despite the effects of uncertainties.

A possible technique to deal with uncertainties is by means of the robust $H_{\infty}$ approach, which has been developed since the beginning of the eighties and has been applied intensely, with successful results, to convex systems $[11,120,127,128]$.

The $H_{\infty}$ approach assumes that the disturbance $d(t) \in \mathbb{R}^{n_{d}}$ belongs to a set of norm bounded functions. The idea is to minimize the worst error that can arise from any disturbance in the following set:

$$
\|d(t)\|_{2}=\left(\int_{0}^{\infty} d^{T}(\tau) d(\tau) d \tau\right)^{1 / 2}
$$

For instance, let us consider a convex model affected by the above sources of uncertainty:

$$
\begin{aligned}
\dot{x}(t) & =A(\theta(t)) x(t)+B(\theta(t)) u(t)+R(\theta(t)) d(t) \\
y(t) & =C x(t)+G d(t)
\end{aligned}
$$

where the meaning of each variable and matrix is kept as previously and the matrices $A(\theta(t)), B(\theta(t))$, $R(\theta(t))$ satisfy the polytopic property:

$$
\left[\begin{array}{l}
A(\theta(t)) \\
B(\theta(t)) \\
R(\theta(t))
\end{array}\right]=\sum_{i=1}^{h} \rho_{i}(\theta(t))\left[\begin{array}{c}
A_{i} \\
B_{i} \\
R_{i}
\end{array}\right], \quad \sum_{i=1}^{h} \rho_{i}(\theta(t))=1, \quad \rho_{i}(\theta(t)) \geq 0 \quad \forall \theta \in \Theta
$$

Let us consider the Luenberger observer given by (52)-(53), for which the dynamics of the estimation error defined as in (55), can be described after some algebraic manipulations as follows:

$$
\dot{e}(t)=(A(\theta(t))-L(\theta(t)) C) e(t)+(R(\theta(t))+L(\theta(t)) G) d(t)
$$

Then, the design problem can be formulated as the one of guaranteeing asymptotic stability of the estimation error (63) while at the same time minimizing, by means of the $H_{\infty}$ technique, the ratio between the $\ell_{2}$ norm of the output vector and the $\ell_{2}$ norm of the disturbance vector against the disturbance vector $d(t)$, that is,

$$
\min _{\gamma>0} \gamma: \frac{\|y\|_{\ell_{2}}}{\|d\|_{\ell_{2}}}<\gamma, \quad\|d\|_{\ell_{2}} \neq 0
$$

where $\gamma>0$ is the prescribed attenuation level (upper bound on the above mentioned ratio). Then, by considering a bound on the $\mathscr{L}_{2}$ gain from $d(t)$ to $e(t)$ given by the Lyapunov function $V(e(t))=e(t)^{T} P e(t), P \succ 0$, the above performance criterion is satisfied if the following holds: 


$$
\dot{V}(e(t))+e(t)^{T} e(t)-\gamma^{2} d(t)^{T} d(t)<0
$$

Similarly to the procedure described above in Section 3.1, the following LMI is obtained from manipulations on (65):

$$
\left[\begin{array}{cc}
\operatorname{He}\left\{P A_{i}-\Xi_{i} C\right\}+I & P E_{i}-\Xi_{i} G \\
* & -\bar{\gamma} I
\end{array}\right] \prec 0
$$

Once solved the above LMI, the observer gain matrix can be computed as $L_{i}=P^{-1} \Xi_{i}$, which achieves an attenuation level $\gamma=\sqrt{\bar{\gamma}}$.

\subsection{Proportional-Integral Observers}

Proportional-integral observers (PIOs) have become popular in recent years due to their robustness against constant or slowly varying disturbances. In a PIO an additional term, which is proportional to the integral of the output estimation error, is added in order to increase the robustness performance [129], as depicted in Figure 6. This term gives an additional degree of freedom that can be used for the estimation of unknown inputs such as disturbances [130,131], battery charge [132] and faults $[133,134]$, among others.

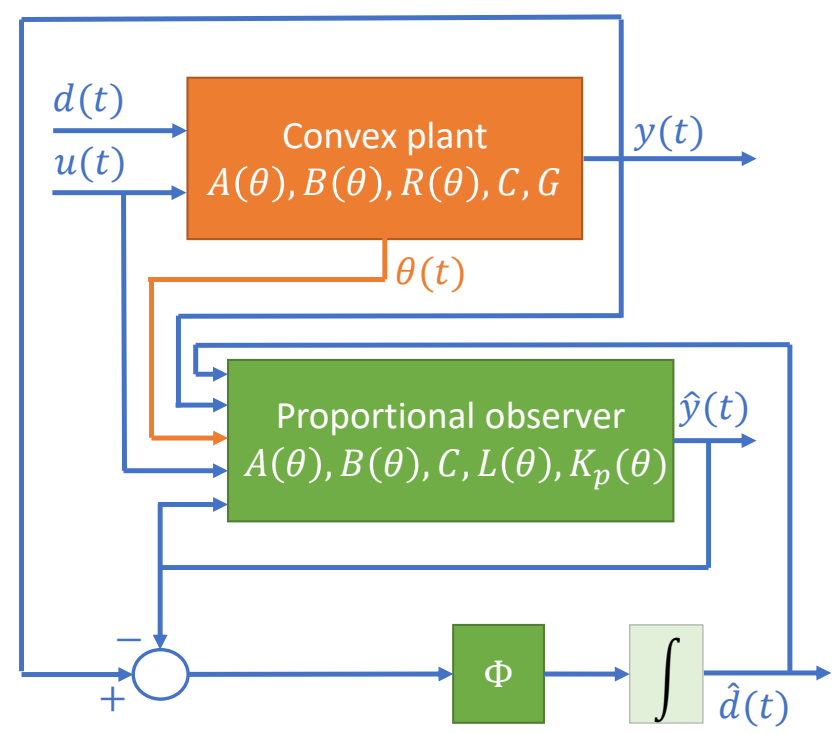

Figure 6. Convex proportional integral observer (PIO) scheme.

A PIO for a system in the form (60)-(61) is described by the following equations:

$$
\begin{aligned}
& \dot{\hat{x}}(t)=A(\theta(t)) x(t)+B(\theta(t)) u(t)+L(\theta(t))(C \hat{x}(t)-y(t))+K_{p}(\theta(t)) \hat{d}(t) \\
& \hat{\hat{d}}(t)=\Phi(y(t)-C \hat{x}(t))
\end{aligned}
$$

where $\hat{x}$ and $\hat{d}$ denote the estimated state and unknown input vectors, respectively and $L(\theta(t))$, $K_{p}(\theta(t))$, and $\Phi$ are the observer gain matrices to be computed. The addition of an integrator provides more robustness to the observer so that it can deal with measurement noise or modeling uncertainties. Let us define the estimation errors as (55) and $e_{d}(t)=d(t)-\hat{d}(t)$. In order to get a suitable design procedure, it can be considered that the unknown input $d(t)$ is varying slowly, which means that $\dot{d}(t) \approx 0$. Then, the dynamics of the estimation errors can be computed as: 


$$
\begin{aligned}
& \dot{e}(t)=(A(\theta(t))-L(\theta(t)) C) e(t)+(R(\theta(t))-L(\theta(t)) G) d(t)-K_{p}(\theta(t)) \hat{d}(t) \\
& \dot{e}_{d}(t)=-\Phi C e(t)-\Phi G d(t)
\end{aligned}
$$

By considering:

$$
\begin{aligned}
& R(\theta(t))-L(\theta(t)) G=K_{p}(\theta(t)) \\
& \Phi G=0
\end{aligned}
$$

and an extended error vector defined as $\bar{e}^{T}(t):=\left[e^{T}(t) e_{d}^{T}(t)\right]^{T}$, the overall error dynamics is rewritten as:

$$
\dot{\bar{e}}(t)=\left(A_{e}(\theta(t))-L_{e}(\theta(t)) C_{e}\right) \bar{e}(t)
$$

with:

$$
A_{e}(\theta(t))=\left[\begin{array}{cc}
A(\theta(t) & K_{p}(\theta(t) \\
0 & 0
\end{array}\right] \quad L_{e}(\theta(t))=\left[\begin{array}{c}
L(\theta(t)) \\
\Phi
\end{array}\right] \quad C_{e}=[C, 0]
$$

Then, by considering a Lyapunov equation $V(\bar{e}(t))=\bar{e}^{T}(t) \mathscr{P} \bar{e}(t)$, the solution is obtained in the LMI formulation, similarly to (56), as:

$$
\operatorname{He}\left\{\mathscr{P} A_{e}(\theta)-W_{e}(\theta) C_{e}\right\} \prec 0 \quad \forall \theta \in \Theta
$$

where $\mathscr{P}=\operatorname{diag}(P, Q), P, Q \succ 0$ and $W_{e}(\theta(t))=\mathscr{P} L_{e}(\theta(t))$. The observer gain matrices are obtained from the solution of (75) as $L_{e}(\theta(t))=\mathscr{P}^{-1} W_{e}(\theta(t))$.

It is worth remarking that the slow variation assumption is very common in the literature. From a practical point of view, it can be relaxed, as done for example in Ref. [135]. It is also worth noticing that later, in Section 4.2, unknown input observers, which allow to obtain asymptotic convergence of the estimation error despite the presence of $d(t)$ without making the assumption that $d(t)$ is approximately constant, will be reviewed.

\subsection{Descriptor Observers}

The observers discussed above are designed for regular systems whose dynamics are represented only by ordinary differential equations. Nevertheless, some mathematical models are composed of both differential and static (algebraic) equations. Designing state observers for descriptor systems is harder than for regular systems because descriptor systems usually have three types of modes (finite dynamic, impulsive and non-dynamic [136]) and the observer must deal with all of them. Nonetheless, there are plenty of fields in which descriptor systems are applied, for example, aircraft modeling [137], complex systems [11], microgrids [138], electrical [9], mechanical and hydraulic systems [136] and biological processes [12], among others. Furthermore, there are some mechanical systems for which possible variations in time of masses and/or inertias rely on a natural descriptor model as in Refs. [139-141]. In these cases, although convex systems can be transformed into a regular system, it has been proved that it is possible to reduce the number of linear models by considering a descriptor representation, which in general makes the LMI-based constraints less conservative [142,143].

A convex descriptor system affected by disturbances is described by

$$
\begin{aligned}
E \dot{x}(t) & =A(\theta(t)) x(t)+B(\theta(t)) u(t)+R(\theta(t)) d(t) \\
y(t) & =C x(t)+G d(t)
\end{aligned}
$$

where $E$ is a constant matrix with $\operatorname{rank}(E)=r \leq n_{x}$. Note that in the particular case of $E=I$, the descriptor system becomes a regular system and the observer can be computed as described 
previously. On the other hand, unlike regular systems, a descriptor system has different modes that are given by differential and algebraic equations. As a result, different types of observability condition should be verified such as R-observability [144], which means that:

$$
\operatorname{rank}\left[\begin{array}{c}
s E-A_{i} \\
C
\end{array}\right]=n_{x} \quad \forall i \in[1,2, \ldots N]
$$

and I-observability [144], that is,

$$
\operatorname{rank}\left[\begin{array}{cc}
E & A_{i} \\
0 & E \\
0 & C
\end{array}\right]=n_{x}+r \quad \forall i \in[1,2, \ldots, N]
$$

R-observability characterizes the ability to reconstruct only the reachable state from the output data. However, due to the algebraic equations, impulsive terms can appear, which are not desirable since they can saturate the state response or, in general, have negative effects on the system. On the other hand, I-observability guarantees the ability to estimate impulse terms given by the algebraic equations [12].

Then if the convex descriptor system is both R- and I-observable, the following observer can be proposed:

$$
\begin{aligned}
\dot{z}(t) & =N(\theta(t)) z(t)+J(\theta(t)) u(t)+L(\theta(t)) y(t) \\
\hat{x}(t) & =z(t)+T_{2} y(t) \\
\hat{y}(t) & =C \hat{x}(t)
\end{aligned}
$$

where $z(t)$ represents the observer state and $\hat{x}(t)$ stands for the estimated states. $N(\theta(t)), J(\theta(t))$, $L(\theta(t))$ and $T_{2}$ are unknown gain matrices of appropriate dimensions to be computed. Based on (76)-(77) and (80)-(82), the estimation error $e(t)$ is:

$$
e(t)=x(t)-\hat{x}(t)=\left(I-T_{2} C\right) x(t)-z(t)-T_{2} G d(t)
$$

Assuming that there exists a matrix $T_{1} \in \mathbb{R}^{n_{x} \times n_{x}}$ such that:

$$
I-T_{2} C=T_{1} E
$$

the estimation error becomes:

$$
e(t)=T_{1} E x(t)-z(t)-T_{2} G d(t) .
$$

Assuming that the disturbances is slowly varying, $\dot{d}(t) \approx 0$, the dynamics of $e(t)$ is given by:

$$
\begin{aligned}
\dot{e}(t)= & T_{1} E \dot{x}(t)-\dot{z}(t) \\
= & T_{1}(A(\theta(t)) x(t)+B(\theta(t)) u(t)+R(\theta(t)) d(t))-(N(\theta(t)) z(t)+J(\theta(t)) u(t)+L(\theta(t)) y(t)) \\
= & \left(T_{1} A(\theta(t))-L(\theta(t)) C-N(\theta(t)) T_{1} E\right) x(t)+\left(T_{1} B(\theta(t))-J(\theta(t))\right) u(t) \\
& +\left(T_{1} R(\theta(t))-L(\theta(t)) G+N(\theta(t)) T_{2} G\right) d(t)+N(\theta(t)) e(t)
\end{aligned}
$$

In order to guarantee convergence to zero of the estimation error, the following conditions are considered: 


$$
\begin{aligned}
& T_{1} A(\theta(t))-L(\theta(t)) C-N(\theta(t)) T_{1} E=0 \\
& T_{1} B(\theta(t))-J(\theta(t))=0
\end{aligned}
$$

After some algebraic manipulations, the following equations equivalences are obtained:

$$
\begin{aligned}
& N(\theta(t))=T_{1} A(\theta(t))+K(\theta(t)) C \\
& \Gamma(\theta(t))=L(\theta(t))-N(\theta(t)) T_{2} \\
& \bar{R}(\theta(t))=T_{1} R(\theta(t))-\Gamma(\theta(t)) G
\end{aligned}
$$

A particular solution of both matrices $T_{1}$ and $T_{2}$ is computed as:

$$
\left[\begin{array}{ll}
T_{1} & T_{2}
\end{array}\right]=\left[\begin{array}{ll}
I_{n_{x}} & 0
\end{array}\right]\left[\begin{array}{l}
E \\
C
\end{array}\right]^{+}
$$

The estimation error becomes:

$$
\dot{e}(t)=N(\theta(t)) e(t)+\bar{R}(\theta(t)) d(t)
$$

and, in order to guarantee robustness, the following $H_{\infty}$ performance criterion is considered:

$$
\dot{V}(e(t))+e(t)^{T} e(t)-\gamma^{2} d(t)^{T} d(t)<0
$$

with attenuation level $\gamma>0$ and quadratic Lyapunov function $V(e(t)):=e(t)^{T} P e(t), P \succ 0$, such that the following BMI is obtained:

$$
\left[\begin{array}{cc}
\operatorname{He}\left\{P T_{1} A(\theta(t))+P K(\theta(t)) C\right\}+I & P T_{1} R(\theta(t))-P \Gamma(\theta(t)) G \\
* & -\gamma I
\end{array}\right] \prec 0
$$

Then, by considering the change of variable $\Xi(\theta(t))=P K(\theta(t))$ and $\Omega=P \Gamma(\theta(t))$, the above LMI becomes:

$$
\left[\begin{array}{cc}
\operatorname{He}\left\{P T_{1} A(\theta(t))+\Xi(\theta(t)) C\right\}+I & P T_{1} R(\theta(t))-\Omega(\theta(t)) G \\
* & -\gamma I
\end{array}\right] \prec 0
$$

\section{Safety in Convex Systems}

Due to the increased demand of safety and reliability in complex systems, fault diagnosis techniques have attracted a great amount of attention in the past few decades. Concerning the recent developments of fault diagnosis for convex systems, hereafter we will review: (i) residual generation for fault detection; (ii) unknown input observers (UIO)-based fault isolation; (iii) observer-based fault estimation; and (iv) multiple model adaptive estimators (MMAEs). Fault tolerant control (FTC) systems aim at maintaining closed-loop stability and desired performances in the face of faults in some components, for example, actuators or sensors. The majority of the literature has focused the attention on LTI systems, although one can find ad-hoc approaches developed for nonlinear systems, see for example, Ref. [145]. It should not be surprising that some recent research has attempted to extend FTC strategies developed originally for LTI systems to the convex case, in order to enlarge their applicability to a wider class of nonlinear systems. This research has focused mainly on the following techniques, which will be reviewed in the following: (i) sliding mode control (SMC); (ii) control reconfiguration; and (iii) virtual actuators/sensors. 


\subsection{Residual Generation for Fault Detection}

Fault detection aims at detecting accurately the appearance of a fault and is usually performed generating residual signals which act as fault indicators [146]. For the following convex system with unknown disturbances $d(t)$ and faults $f(t)$ :

$$
\begin{aligned}
& \dot{x}(t)=A(\theta(t)) x(t)+B(\theta(t)) u(t)+R(\theta(t)) d(t)+F(\theta(t)) f(t) \\
& y(t)=C x(t)+G d(t)+H f(t)
\end{aligned}
$$

let us consider a detection filter with the following structure:

$$
\begin{aligned}
& \dot{z}(t)=N(\theta(t)) z(t)+J(\theta(t)) u(t)+L(\theta(t)) y(t) \\
& \hat{x}(t)=z(t)-E y(t) \\
& \hat{y}(t)=C \hat{x}(t)
\end{aligned}
$$

where $N(\theta(t)), J(\theta(t)), L(\theta(t))$ are filter gains to be determined through design. By defining the estimation error signal $e(t)=x(t)-\hat{x}(t)$, the residual signal $r(t)=y(t)-\hat{y}(t)$ and the matrix $T=I+E C$, if the following constraints hold:

$$
\begin{aligned}
& \text { TA }(\theta(t))-N(\theta(t)) T-L(\theta(t)) C=0 \\
& T B(\theta(t))-J(\theta(t))=0 \\
& E\left[\begin{array}{ll}
G & H
\end{array}\right]=0
\end{aligned}
$$

then one obtains that the residual has a dynamics described by:

$$
\begin{aligned}
& \dot{e}(t)=N(\theta(t)) e(t)+B_{d}(\theta(t)) d(t)+B_{f}(\theta(t)) f(t) \\
& r(t)=C e(t)+D d(t)+H f(t)
\end{aligned}
$$

with:

$$
\begin{aligned}
& B_{d}(\theta(t))=[\operatorname{TR}(\theta(t)-L(\theta(t)) G-N(\theta(t)) E G)] \\
& B_{f}(\theta(t))=[T F(\theta(t)-L(\theta(t)) H-N(\theta(t)) E H)]
\end{aligned}
$$

Then, in order to achieve the fault detection goal, one must ensure the asymptotic stability of the error system while making the signal $r(t)$ as sensitive as possible to faults and as insensitive as possible to disturbances, which is usually achieved by means of a mix of $H_{\infty}$ and $H_{-}$index optimization. This approach was initially proposed for filter design in the full-frequency domain, see for example, Refs. [147, 148]. However, for some practical systems, fault and disturbance frequencies ranges are known beforehand, which motivated recent research on filter design in a finite-frequency domain [149-151], using the so-called generalized Kalman-Yakubovich-Popov (GKYP) lemma [152]. Another recent line of research worth of mentioning is the one that investigates the behavior of the fault detection observer when unmeasurable scheduling parameters are considered, see for example, Ref. [153].

\subsection{Unknown Input Observers-Based Fault Isolation}

In the last years, UIOs have shown to be a promising technique for fault detection purposes, due to their ability to provide the system state estimate even in the presence of unknown inputs, such as faults and disturbances. The approaches proposed for UIO design can be basically split into two classes: in the first one, the state estimation is decoupled from the unknown inputs, for example, by means of some structural conditions [154]. In the second case, joint estimation of the state and unknown inputs is achieved [155]. 
Let us consider the following convex system (for the sake of simplicity, the whole state is assumed to be measured):

$$
\begin{aligned}
\dot{x}(t) & =A(\theta(t)) x(t)+B(\theta(t)) u(t)+F(\theta(t)) f(t) \\
y(t) & =x(t)
\end{aligned}
$$

and let $R(\theta(t))$ and $H(\theta(t))$ be some given matrix functions. Let us choose:

$$
\begin{aligned}
& T(\theta(t))=I-R(\theta(t)) \\
& S_{1}(\theta(t))=R(\theta(t)) A(\theta(t))-H(\theta(t)) \\
& S_{2}(\theta(t))=H(\theta(t)) T(\theta(t))
\end{aligned}
$$

then:

$$
\begin{aligned}
& \dot{z}(t)=H(\theta(t)) z(t)+R(\theta(t)) B(\theta(t)) u(t)+[S(\theta(t))-\dot{T}(\theta(t))] y(t) \\
& \hat{x}(t)=z(t)+T(\theta(t)) y(t)
\end{aligned}
$$

where $\dot{T}(\theta(t))$ is the time derivative of $T(\theta(t))$ and:

$$
S(\theta(t))=S_{1}(\theta(t))+S_{2}(\theta(t))
$$

is an unknown input observer for (107)-(108) [156], for which the dynamics of the estimation error $e(t)=x(t)-\hat{x}(t)$ is given by:

$$
\dot{e}(t)=H(\theta(t)) e(t)+R(\theta(t)) F(\theta(t)) f(t)
$$

In fact, taking into account (107)-(108) and (112)-(113), one finds:

$$
\begin{aligned}
\dot{e}(t)= & {[A(\theta(t))-S(\theta(t))-T(\theta(t)) A(\theta(t))] x(t)-H(\theta(t)) z(t) } \\
& +[I-R(\theta(t))-T(\theta(t))] B(\theta(t)) u(t)+[I-T(\theta(t))] F(\theta(t)) f(t)
\end{aligned}
$$

which, using (109)-(111), can be rewritten as follows:

$$
\dot{e}(t)=[H(\theta(t))-H(\theta(t) T(\theta(t)))] x(t)-H(\theta(t)) z(t)+R(\theta(t)) F(\theta(t)) f(t)
$$

Then, it is easy to check that (115) follows from (117) taking into account (113).

The main feature of the estimation error dynamics in (115) is that convergence of $e(t)$ to zero when $f(t)=0$ can be ensured by a proper choice of the matrix $H(\theta(t))$ (for example, as a diagonal matrix with strictly negative parameter-varying elements on the main diagonal). Moreover, the matrix $R(\theta(t))$ can be used to constrain the range of the matrix $R(\theta(t)) F(\theta(t))$, in such a way that different directions of $e(t)$ can be assigned to different faults, such that not only fault detection but also fault isolation can be achieved.

In the last years, one can recognize a trend in research that goes towards robustification of this technique, which was started by Ref. [157]. For instance, a few recent works have merged UIOs with interval observers [158-160], in such a way that instead of a single trajectory for the estimation error, lower and upper bounds which are compatible with the uncertainty are computed. On the other hand, other works have considered the case in which the scheduling variables are measured inexactly, see for example, Refs. [128,161,162]. Further improvements have been provided by Ref. [163], who have not restricted the parameter dependency of the UIO to mimic the one of the system, so that the decoupling conditions can be relaxed and have also considered the case in which the output equation of the convex system is not restricted to be parameter-independent. 


\subsection{Observer-Based Fault Estimation}

As the name itself suggests, in observer-based fault estimation techniques, an observer is used to estimate the fault as though as if it were another (unmeasurable) state of the system. In order to exemplify the main idea behind these techniques, let us consider the following convex system:

$$
\begin{aligned}
& \dot{x}(t)=A(\theta(t)) x(t)+B(\theta(t)) u(t)+F(\theta(t)) f(t) \\
& y(t)=C x(t)
\end{aligned}
$$

and let us assume that the dynamics of $f(t)$ is described by:

$$
\dot{f}(t)=A_{f} f(t)
$$

with known matrix $A_{f}$ (this assumption can be relaxed using, for example, an interval formulation). Then, it is possible to consider an augmented state $\bar{x}(t)=\left[x(t)^{T}, f(t)^{T}\right]^{T}$ such that the resulting augmented system is described by:

$$
\begin{aligned}
\dot{\bar{x}}(t) & =\bar{A}(\theta(t)) \bar{x}(t)+\bar{B}(\theta(t)) u(t) \\
y(t) & =\bar{C} x(t)
\end{aligned}
$$

with:

$$
\bar{A}(\theta(t))=\left[\begin{array}{cc}
A(\theta(t)) & F(\theta(t)) \\
0 & A_{f}
\end{array}\right] \quad \bar{B}(\theta(t))=\left[\begin{array}{c}
B(\theta(t)) \\
0
\end{array}\right] \quad \bar{C}=\left[\begin{array}{ll}
C & 0
\end{array}\right]
$$

Hence, a state observer designed to provide an estimate $\hat{\bar{x}}(t)$ of $\bar{x}(t)$ would provide an estimate $\bar{f}(t)$ of $f(t)$.

Among recent works developing further this concept, an adaptive polytopic observer which could estimated time-varying actuator faults was presented in Ref. [164] for convex descriptor systems, differing from most of other papers which assume generally that the actuator faults are constant. Sliding mode observers have been investigated by Refs. $[165,166]$, which have considered the case of erroneous scheduling parameters. The case in which the fault's frequency content is not distributed within the whole frequency domain but in a finite interval of frequencies was addressed by Ref. [167] based on the GKYP lemma. An improvement of the design conditions has been brought by Ref. [168], which have developed a robust fault estimator via homogeneous polynomially parameter-dependent Lyapunov functions. It is worth highlighting that, although the majority of the results found in the literature consider the case of additive faults, some recent work has proposed a switched observer formulation to estimate actuator multiplicative faults in discrete-time convex systems [135]. Successful applications of observer-based fault estimation, either using high-fidelity simulations or through experimental validation, can be found in the areas of aviation [165,166], bioreactors [12], distillation columns [169], automotive suspension systems [170] and renewable microgrids [171,172].

\subsection{Multiple Model Adaptive Estimators}

The main idea behind MMAEs is to choose a set of models that represent the possible system behavior patterns and to obtain the state estimate as a combination of the estimates obtained from local state observers which run in parallel, each one based on the individual models that match these patterns $[173,174]$. The above mentioned combination is achieved as a weighted sum, where the weights represent the likelihood that the corresponding model is indeed true. Under certain conditions, the weight associated with the correct model converges to 1 , while the other weights converge to 0 , which allows an adaptive identification of the correct model [175]. This approach has been developed for discrete-time systems and it is exemplified hereafter. 
Following Ref. [176], let us consider the discrete-time convex system:

$$
\begin{aligned}
& x(k+1)=A(\zeta(k), \theta(k)) x(k)+B(\zeta(k), \theta(k)) u(k) \\
& y(k)=C(\zeta(k), \theta(k)) x(k)
\end{aligned}
$$

where using standard notation, $k \in \mathbb{Z}$ denotes a sample. Moreover, $\zeta(k)$ denotes an uncertain parameter, for which a finite set of candidate parameter values $\left\{\zeta_{1}, \zeta_{2}, \ldots, \zeta_{N}\right\}$ is considered.

For the system (123)-(124), state estimation is achieved by means of the following convex MMAE [176]:

$$
\begin{aligned}
\hat{x}(k) & =\sum_{i=1}^{h} p_{i}(k) \hat{x}\left(k \mid \zeta_{i}\right) \\
\hat{y}(k) & =\sum_{i=1}^{h} p_{i}(k) \hat{y}\left(k \mid \zeta_{i}\right) \\
\hat{\zeta}(k) & =\zeta_{i^{*}(k)}, \quad i^{*}(k)=\arg \max _{i \in\{1, \ldots, h\}} p_{i}(k)
\end{aligned}
$$

where $\hat{x}(k), \hat{y}(k)$ and $\hat{\zeta}(k)$ denote the estimates of the state $x(k)$, the output $y(k)$ and the unknown parameter vector $\zeta$, respectively and $p_{i}(k)$ are dynamic weights, which can be interpreted as a time-varying indicator of how likely it is that $\zeta=\zeta_{i}$. In (125)-(126), each $\hat{x}\left(k \mid \zeta_{i}\right), \hat{y}\left(k \mid \zeta_{i}\right)$ correspond to local estimates, obtained under the assumption that $\zeta=\zeta_{i}$.

The dynamic weights $p_{i}(k)$ appearing in (125)-(127) can be generated as follows:

$$
p_{i}(k+1)=\frac{p_{i}(k) \beta_{i}(k) e^{-\omega_{i}(k)}}{\sum_{j=1}^{N} p_{j}(k) \beta_{j}(k) e^{-\omega_{j}(k)}}
$$

where $\beta_{i}(k)$ is a positive weighting matrix function and $\omega_{i}(k)$ is the error measuring function, which describes how different is each local output estimate $\hat{y}\left(k \mid \zeta_{i}\right)$ from the observed output $y(k)$.

The above described convex MMAE, for which a conceptual scheme is provided in Figure 7 , has some relevant properties. First of all, if $p_{i}(0)>0 \forall i \in\{1, \ldots, h\}$, it can be proven that all the weights $p_{i}(k)$ generated by (128) are non-negative, uniformly bounded and contained in $[0,1]$, with $\sum_{i=1}^{h} p_{i}(k)=1, \forall k>0$. Moreover, it can be demonstrated that under some conditions the parameter estimate $\hat{\zeta}(k)$ will converge to a value $\zeta_{i}^{*}$ with $p_{i}^{*}(k) \rightarrow 1$ as $k \rightarrow \infty$, which corresponds to the local estimate that exhibits the smallest error measuring function.

These properties have been exploited for fault identification purposes by Ref. [177], where it was shown that a convex MMAE could be used to achieve icing diagnosis in unmanned aerial vehicles (UAVs) with the relevant feature that information about the icing location could be obtained. In this case, the idea is to assign different faulty models to different parameters $\zeta_{i}$, in such a way that the dynamic weights would suggest which model is the one that fits data coming from the sensors the best. A similar idea was employed in Ref. [178], where a bank of observers, each one corresponding to a system description taking into account the presence of a particular fault, was used to address the problem of fault detection and isolation in near-space vehicles (NSVs) with actuator faults. 


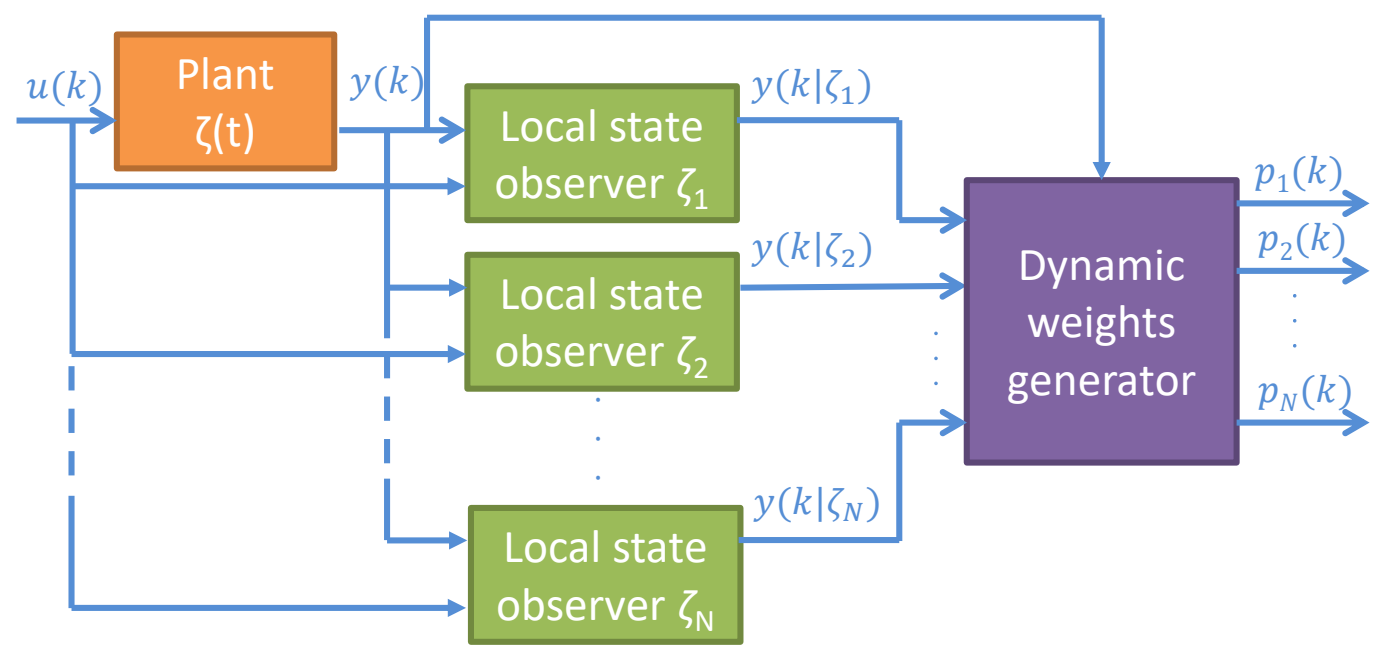

Figure 7. Multiple model adaptive estimator (MMAE) conceptual scheme.

\subsection{Sliding Mode Fault Tolerant Control}

The robustness of sliding mode control (SMC) against matched uncertainties makes it an interesting choice for FTC [179], although its direct application is impeded by the loss of regularity of the sliding mode when complete losses of actuators are considered. In fact, the first applications of SMC to convex systems were in a fault-free context [180]. The above mentioned problem was solved for overactuated systems by Ref. [181] by means of control allocation (CA), which provides an effective mechanism for distributing a virtual control signal among the available actuators.

More specifically, a convex plant subject to actuator faults represented by a diagonal semipositive definite matrix $W(t)$ with diagonal entries that represent the effectiveness level of actuators was considered in Ref. [181], as follows:

$$
\dot{x}(t)=A(\theta(t)) x(t)+B_{f} E(\theta(t)) W(t) u(t)
$$

where $E(\theta)$ is invertible for all $\theta \in \Theta$ and $B_{f}$ is factored as $B_{f}=\left[B_{1}, B_{2}\right]^{T}$ with $B_{2} B_{2}^{T}=I_{l}, l<n_{u}$ and $\left\|B_{2}\right\|>\left\|B_{1}\right\|$, so that $B_{2}$ represents the dominant contribution of the distribution of the control action within the channels of the system.

For the system (129), the control law is chosen as (see Figure 8 for an illustrative scheme):

$$
u(t)=-(E(\theta(t)))^{-1} B_{2}^{T}\left(B_{2} E(\theta(t)) \hat{W}(t)(E(\theta(t)))^{-1} B_{2}^{T}\right)^{-1}\left(v_{l}(t)+v_{n}(t)\right)
$$

where $\hat{W}(t)$ is an estimate of $W(t), v_{l}(t)$ is the linear component of the virtual control, chosen to be a standard state-feedback $v_{l}(t)=-F x(t)$ and $v_{n}(t)$ is the nonlinear discontinuous part, which induces sliding and provides robustness:

$$
v_{n}(t)=-\kappa(t) \frac{\sigma(t)}{\|\sigma(t)\|} \quad \text { for } \sigma(t) \neq 0
$$

where $\kappa(t)$ is an adaptive modulation function given by:

$$
\begin{aligned}
& \kappa(t)=\|F\|\|x(t)\| \bar{\kappa}(t)+\eta \\
& \dot{\bar{\kappa}}(t)=-\beta \bar{\kappa}(t)+\gamma \epsilon_{0}\|F\|\|x(t)\|\|\sigma(t)\|
\end{aligned}
$$


with $\beta, \gamma, \epsilon_{0}, \eta$ positive scalars and $\sigma$ defines the sliding surface $\sigma(t)=0$ :

$$
\sigma(t)=B_{2}\left(B_{f}^{T} B_{f}\right)^{-1} B_{f}^{T}\left(x(t)-x(0)-\int_{0}^{t}\left(A(\theta(\tau))-\left[\begin{array}{c}
B_{1} B_{2}^{T} \\
I_{l}
\end{array}\right] F\right) x(\tau) d \tau\right)
$$

Finally, Ref. [145] shows that if $F$ is designed such that the fault-free closed-loop system is quadratically stable, then it is possible to prove that for any faults/failures inside the set:

$$
\mathcal{W}_{\epsilon}=\left\{\left(w_{1}, \ldots, w_{n_{u}}\right) \in[0,1] \times \ldots \times[0,1]: H(\theta)^{T} H(\theta)>\epsilon I\right\}
$$

with $\epsilon$ small scalar which satisfies $0<\epsilon \ll 1$ and $H(\theta)=B_{2} E(\theta) W(t)(E(\theta))^{-1} B_{2}^{T}$, the sliding motion will be stable if:

$$
\gamma_{0} \gamma_{1}\left(1+\frac{c}{\sqrt{\epsilon}}\right)<1
$$

where $\gamma_{0}$ is the $\mathcal{L}_{2}$ gain of $\tilde{G}(s)=F\left(s I-A(\theta)+B_{v} F\right)^{-1}\left[I_{n-l}, 0\right]^{T}, \gamma_{1}=\left|B_{1}\right|$ (which, by assumption is small) and $c$ represents the worst-case condition number (over $\Theta$ ) of $E(\theta)$.

The design of the state-feedback controller in Ref. [181] was based on the assumption that all the plant states are available. This assumption was later relaxed by Ref. [182], where an unknown input observer (UIO) was used to estimate the unavailable plant states. Further research has led to develop some conditions based on the Lyapunov-Krasovskii functional approach that do not only guarantee the passivity and asymptotical stability of the closed-loop system but also cover the issue of actuator saturation and the existence of time-varying delays [183].

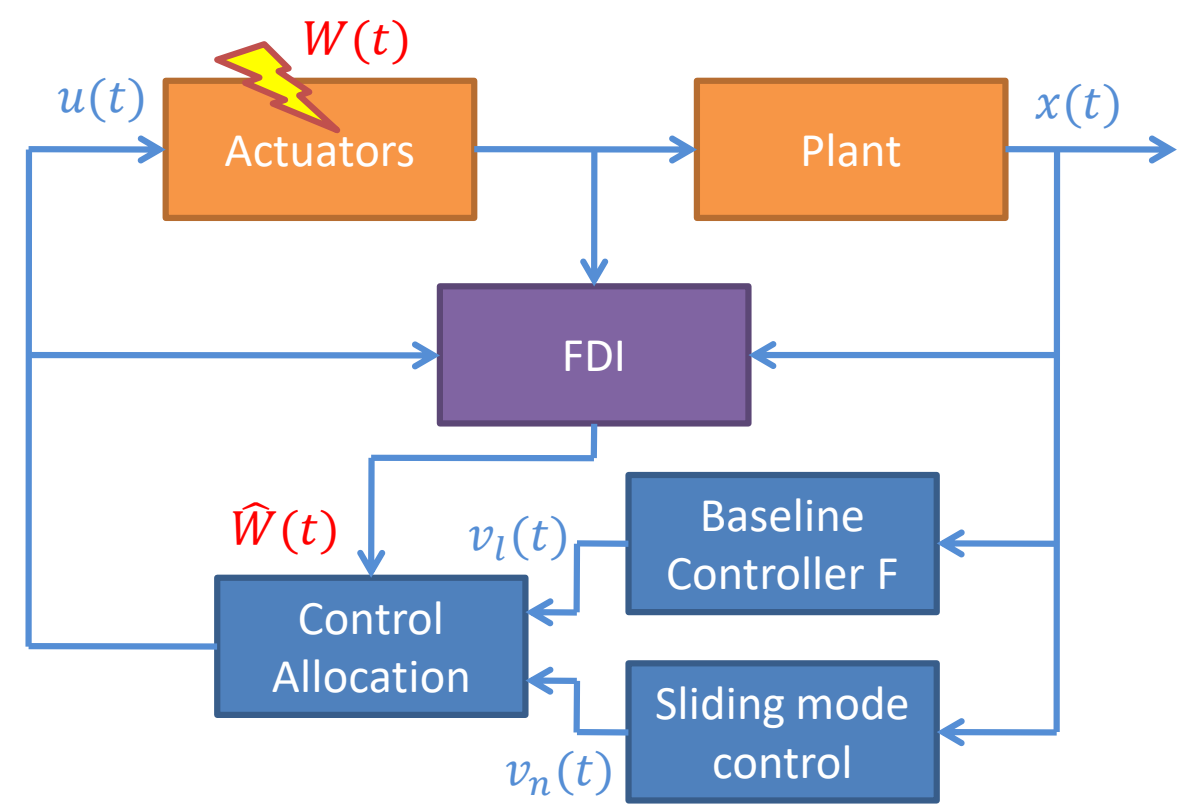

Figure 8. Sliding mode fault tolerant control (FTC) scheme.

\subsection{Fault Tolerant Control Based on Controller Reconfiguration}

On the other hand, as the name itself suggests, in controller reconfiguration, some modification of the control law is performed in order to compensate for the fault effect and make the faulty system behave as close as possible to the nominal system. The reconfiguration can be performed either by considering the fault estimation $\hat{f}(t)$ as an additional scheduling variable $\theta_{f}(t)$, as in Refs. $[26,184,185]$ or by introducing a component in the control law, which is responsible to achieve fault tolerance, 
as proposed by Refs. [186-189]. In the first case, if we restrict our attention to a state-feedback control law (for the sake of simplicity), then it would have the following structure:

$$
u(t)=K\left(\theta(t), \theta_{f}(t)\right) x(t)
$$

with the advantage that fault tolerance would be achieved employing exactly the same LMI-based techniques employed for standard control design. On the other hand, in the second case, the control law is obtained as follows (see Figure 9):

$$
u(t)=u_{n}(t)+u_{f}(t)
$$

where $u_{n}(t)$ is the nominal state-feedback controller in fault-free condition and $u_{f}(t)$ is used to accommodate the faults. The advantage of this approach lies in that it eases the integrated design of fault estimator and fault tolerant controller, as discussed deeply in Ref. [188]. In order to illustrate this fact, let us consider the following convex system, which is a simplification of the class of systems considered in Ref. [188] by neglecting disturbances and parametric uncertainties in the state matrix:

$$
\begin{aligned}
& \dot{x}(t)=A(\theta(t)) x(t)+B(\theta(t)) u(t)+F(\theta(t)) f_{a}(t) \\
& y(t)=C x(t)+F_{s} f_{s}(t)
\end{aligned}
$$

where $f_{a}(t)$ and $f_{s}(t)$ denote actuator and sensor faults, respectively. By augmenting the state as $\bar{x}(t)=\left[x(t), f_{a}(t), f_{s}(t)\right]^{T}$, the system (139)-(140) becomes:

$$
\begin{aligned}
\dot{\bar{x}}(t) & =\bar{A}(\theta(t)) \bar{x}(t)+B(\theta(t)) u(t) \\
y(t) & =\bar{C} \bar{x}(t)
\end{aligned}
$$

for which an observer can be proposed, as follows:

$$
\begin{aligned}
& \dot{z}(t)=M(\theta(t)) z(t)+J(\theta(t)) u(t)+L(\theta(t)) y(t) \\
& \hat{x}(t)=z(t)+H y(t)
\end{aligned}
$$

where $z(t)$ and $\hat{x}(t)$ are the observer internal state and the estimate of $\bar{x}(t)$, respectively. Under the assumption that:

$$
\begin{aligned}
& L(\theta(t))=L_{1}(\theta(t))+L_{2}(\theta(t)) \\
& L_{2}(\theta(t))=\left(\Xi \bar{A}(\theta(t))-L_{1}(\theta(t)) \bar{C}\right) H \\
& M(\theta(t))=\Xi \bar{A}(\theta(t))-L_{1}(\theta(t)) \bar{C} \\
& J(\theta(t))=\Xi \bar{B}(\theta(t))
\end{aligned}
$$

with $\Xi=I-H \bar{C}$, the dynamics of the estimation error $e(t)=x(t)-\hat{x}(t)$ is described by:

$$
\dot{e}(t)=M(\theta(t)) e(t)=\left[\Xi \bar{A}\left(\theta(t)-L_{1}(\theta(t)) \bar{C}\right)\right] e(t)
$$

If the control law is chosen as:

$$
u(t)=K(\theta(t)) \hat{x}(t)=\left[\begin{array}{ll}
K_{x}(\theta(t)) & K_{f}(\theta(t))
\end{array}\right] \hat{x}(t)
$$

where $K_{x}(\theta(t))$ and $K_{f}(\theta(t))$ are the state-feedback and actuator fault compensation gains respectively, then if $K_{f}(\theta(t))$ is chosen as $K_{f}(\theta(t))=-B(\theta(t))^{\dagger} F(\theta(t))$ (under the assumption that the actuator fault $f_{a}(t)$ is in the range space of the control input), one obtains: 


$$
\dot{x}(t)=\left[A(\theta(t))+B(\theta(t)) K_{x}(\theta(t))\right] x(t)+E(\theta(t)) e(t)
$$

with:

$$
E(\theta(t))=\left[\begin{array}{lll}
-B(\theta(t)) K_{x}(\theta(t)) & F(\theta(t)) & 0
\end{array}\right]
$$

On the other hand, the sensor fault can be compensated as:

$$
y_{c}(t)=y(t)-F_{s} \hat{f}_{s}(t)
$$

where $y_{c}(t)$ is the compensated system output and $\hat{f}_{s}(t)$ is the sensor fault estimate. Since (149) and (151) describe an autonomous convex system, the integrated FE/FTC design can be formulated as an LMI-based stabilization problem ( $H_{\infty}$ optimization if there are uncertainties and/or disturbances).

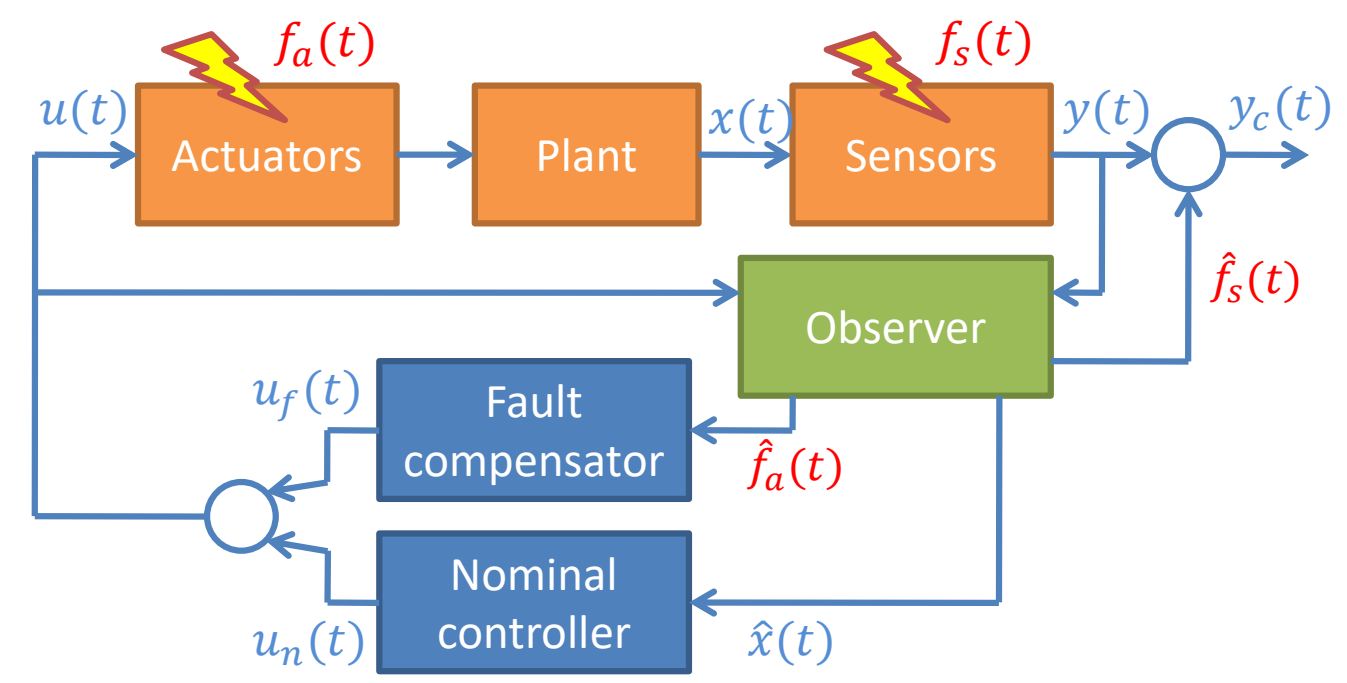

Figure 9. Controller reconfiguration FTC scheme.

\subsection{Fault-Hiding via Virtual Actuators and Virtual Sensors}

Contrarily to the previously described approach, the fault-hiding paradigm aims at reconfiguring the faulty plant instead of the controller/observer when a fault occurs [88]. The reconfiguration block hides the fault from the controller/observer point of view, such that it will see the same plant as before the fault and thus can be kept without modifying or retuning it (see Figure 10). The advantage of doing so is that fault tolerance can be added to an already existing control scheme by means of a plug-and-play philosophy. In case of actuator faults, the reconfiguration block is named virtual actuator [190], whereas it is named virtual sensor in the case of sensor faults [191]. Although virtual sensors and virtual actuators were initially considered separately, an overall scheme that employs both of them in order to tolerate simultaneous actuator and sensor faults was later developed [192,193]. Some recent work has also studied issues related to the existence of input constraints (saturations) and fault isolation delays [194].

Let us consider the following convex system:

$$
\begin{aligned}
\dot{x}(t) & =A(\theta(t)) x(t)+B(\theta(t)) W(t)\left(u(t)+f_{a}(t)\right) \\
y(t) & =V(t) C x(t)+f_{s}(t)
\end{aligned}
$$

where, consistently with the previously described approaches, $W(t)$ and $V(t)$ denote losses of effectiveness in the actuators and sensors, respectively, whereas $f_{a}(t)$ and $f_{s}(t)$ denote additive actuator/sensor faults. 


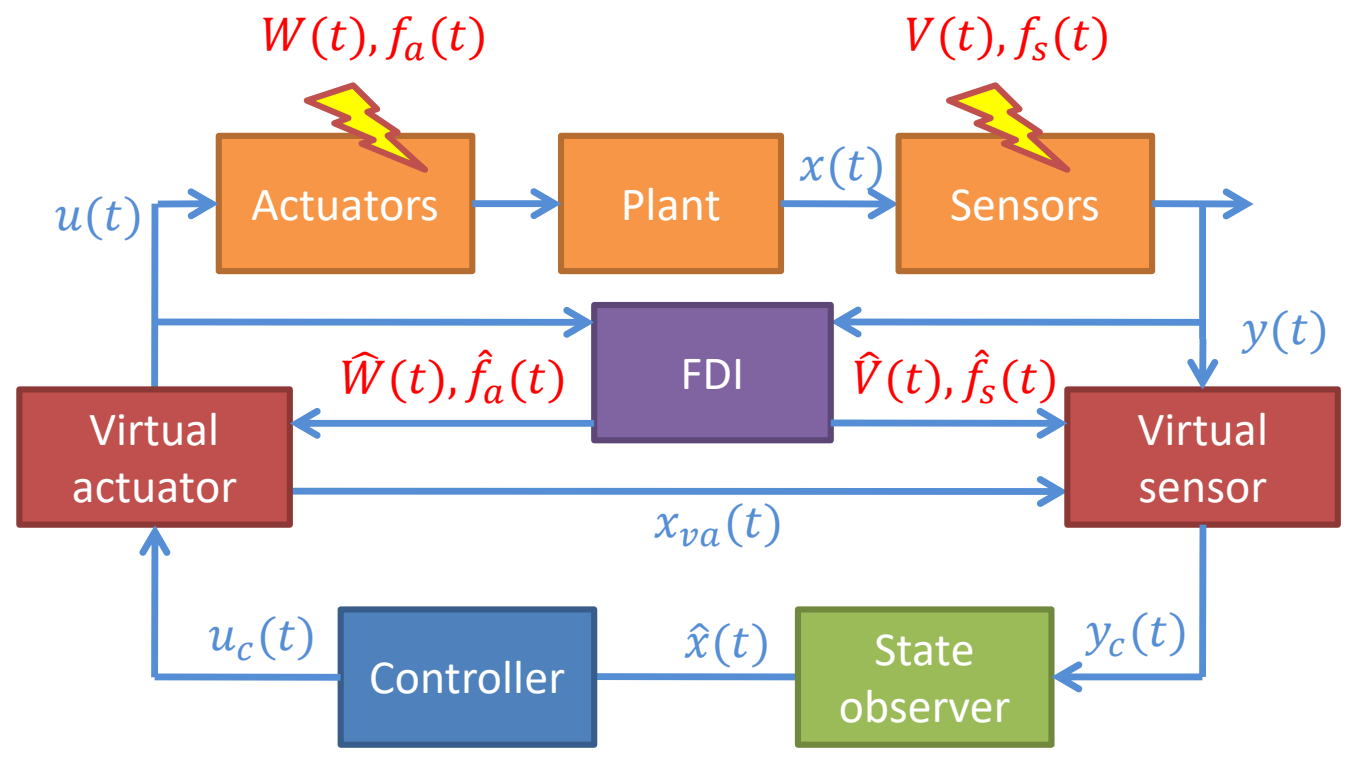

Figure 10. FTC using virtual sensors and virtual actuators.

The structure of the convex virtual actuator depends on the following rank condition $(\hat{W}$ denotes an estimation of $W$ ) [192]:

$$
\operatorname{rank}(B(\theta(t) \hat{W}(t)))=\operatorname{rank}(B(\theta(t))) \quad \forall \theta \in \Theta
$$

which describes whether fault tolerance can be achieved through a simple redistribution of the control inputs. In the first case, the reconfiguration structure is as follows:

$$
u(t)=N_{v a}(\theta(t)) u_{c}(t)-\hat{f}_{a}(t)
$$

where $\hat{f}_{a}(t)$ is an estimation of $f_{a}(t)$ and $N_{v a}(\theta(t))$ is given by:

$$
N_{v a}(\theta(t))=[B(\theta(t)) \hat{W}(t)]^{\dagger} B(\theta(t))
$$

In case (156) does not hold, the virtual actuator becomes a dynamical system with state equation:

$$
\dot{x}_{v a}(t)=\left[A(\theta(t))+B^{*}(\theta(t)) M_{v a}(\theta(t))\right] x_{v a}(t)+\left[B\left(\theta(t)-B^{*}(\theta(t))\right)\right] u_{c}(t)
$$

and output equation (reconfiguration structure):

$$
u(t)=N_{v a}(\theta(t))\left[u_{c}(t)-M_{v a}(\theta(t)) x_{v a}(t)-\hat{f}_{a}(t)\right]
$$

where $x_{v a}(t)$ is the virtual actuator state, $M_{v a}(\theta(t))$ denotes the virtual actuator gain and the matrix $B^{*}(\theta(t))$ is obtained as:

$$
B^{*}(\theta(t))=B(\theta(t)) \hat{W}(t) N_{v a}(\theta(t))
$$

Similarly, the structure of the virtual sensor depends on the following rank condition $(\hat{V}$ is the estimation of $V$ ) [192]:

$$
\operatorname{rank}(\hat{V}(t) C)=\operatorname{rank}(C)
$$

so that if it holds, then the virtual sensor is a static block, whereas if the above condition does not hold, then it is a dynamical system with internal state $x_{v s}(t)$ and dynamics described by the equations: 


$$
\begin{aligned}
\dot{x}_{v s}(t)=\left[A(\theta(t))+M_{v s}(\theta(t)) C^{*}\right] x_{v s}(t)+B(\theta(t)) u_{c}(t) \\
-M_{v s}(\theta(t)) N_{v s}(t)\left(y(t)+\hat{V}(t) C x_{v a}(t)-\hat{f}_{s}(t)\right) \\
y_{c}(t)=N_{v s}(t)\left(y(t)+\hat{V}(t) C x_{v a}(t)-\hat{f}_{s}(t)\right)+\left(C-C^{*}\right) x_{v s}(t)
\end{aligned}
$$

where $\hat{f}_{s}(t)$ denotes an estimation of $f_{s}(t), M_{v s}(\theta(t))$ is the virtual sensor gain and:

$$
\begin{aligned}
& N_{v s}(t)=C[\hat{V}(t) C]^{\dagger} \\
& C^{*}=N_{v s}(t) \hat{V}(t) C
\end{aligned}
$$

Then, it is possible to show that if the control loop consists of a state-feedback law with controller gain $K(\theta(t))$ and a Luenberger observer with gain $L(\theta(t))$, then thanks to the introduction of the virtual actuator/sensor in the loop, one can find an appropriate similarity transformation of the overall augmented state such that the dynamics in the new state coordinates $\breve{x}$ is described by:

$$
\dot{\check{x}}(t)=\left[\begin{array}{cccc}
A(\theta)+M_{v s}(\theta) C^{*} & 0 & 0 & 0 \\
\star & A(\theta)+L(\theta) C & 0 & 0 \\
\star & \star & A(\theta)+B(\theta) K(\theta) & 0 \\
\star & \star & \star & A(\theta)+B^{*}(\theta) M_{v a}(\theta)
\end{array}\right] \breve{x}(t)
$$

where $\star$ denotes some generic non-zero terms, which is in a block-triangular structure. Then, since $A(\theta)+L(\theta) C$ and $A(\theta)+B(\theta) K(\theta)$ are already stable due to the stability of the faultless system, one can ensure overall stability under fault occurrence by designing the gains $M_{v s}(\theta)$ and $M_{v a}(\theta)$ so that $A(\theta)+M_{\nu s}(\theta) C^{*}$ and $A(\theta)+B^{*}(\theta) M_{\nu a}(\theta)$ are stable (the reader is referred to Ref. [192] for further details on the method, along with a discussion about the quadratic stability of block-triangular convex systems).

Finally, it is worth mentioning that some recent works have combined model predictive control (MPC) with the convex formulation in order to take into account possible input and state constraints associated to actuator saturation and other physical limitations [195,196]. The convex MPC framework has been used to go one step further than FTC, that is, to perform health-aware control on the basis of the information about the system reliability provided by a prognosis and health management (PHM) module $[197,198]$. This type of control strategy increases the overall reliability, anticipates the apparition of faults and reduces the operational costs.

\section{Conclusions}

In this paper, we have performed a review of the most applied techniques in control, observation and safety of convex systems. With this terminology we have wished to unify the concepts of linear parameter varying and Takagi-Sugeno systems, with the purpose of allowing the reader to taste all the flavors of techniques offered by the humongous existing literature about these classes of systems. Due to the huge amount of papers, the review is in no way meant to be exhaustive but it is meant to be a helpful document to look for any reader who wishes to locate himself/herself in this field and learn about the main used techniques. We feel that we have done our best to provide a discussion about the state-of-the-art of the topic. However, in spite of our best efforts, many publications could not be included and for this reason, we would like to apologize in advance for any omission.

In addition, it is important to mention that this paper is mainly focused on discussing the advances of polytopic convex systems. However, it is acknowledged that other approaches that lead to an LPV representation exist, such as grid-based LPV [199], linear fractional transformation (LFT)-based LPV [200,201], polynomial LPV approaches [202] and tensor model-based transformation [203,204], among others. Also, the reader should note that, throughout the review, only methods based on 
quadratic Lyapunov functions have been discussed. Nevertheless, less conservative solutions can be obtained based on non-quadratic Lyapunov functions, for example, the polyquadratic, as proposed in Refs. [69-71]. In general, all these topics are currently investigated and, therefore, the above references are recommended to the interested reader.

Author Contributions: Conceptualization, F.-R.L.-E., D.R., and G.V.-P.; investigation, F.-R.L.-E., D.R., and G.V.-P.; writing-original draft preparation, F.-R.L.-E., D.R., and G.V.-P.; writing-review and editing F.-R.L.-E., D.R., and G.V.-P.

Funding: This work has been supported by Tecnológico Nacional de México grants 6723.18-P and 5400.19-P, the Instituto de Ciencia Tecnológia e Innovación, Chiapas (ICTIECH) 1123/2019. This work has been partially funded by the Spanish State Research Agency (AEI) and the European Regional Development Fund (ERFD) through the projects SCAV (ref. MINECO DPI2017-88403-R) and DEOCS (ref. MINECO DPI2016-76493), and also by AGAUR ACCIO RIS3CAT UTILITIES 4.0 - P7 SECUTIL. This work has been also supported by the AEI through the Maria de Maeztu Seal of Excellence to IRI (MDM-2016-0656) and the grant Juan de la Cierva-Formacion (FJCI-2016-29019).

Conflicts of Interest: The authors declare no conflict of interest.

\section{References}

1. Shamma, J.; Athans, M. Guaranteed properties for nonlinear gain scheduled control systems. In Proceedings of the 27th IEEE Conference on Decision and Control, Austin, TX, USA, 7-9 December 1988; Volume 3, pp. 2202-2208.

2. Shamma, J.; Athans, M. Analysis of gain scheduled control for nonlinear plants. IEEE Trans. Autom. Control 1990, 35, 898-907. [CrossRef]

3. Shamma, J. An Overview of LPV Systems. In Control of Linear Parameter Varying Systems with Applications; Mohammadpour, J., Scherer, C.W., Eds.; Springer: Boston, MA, USA, 2012; pp. 3-26.

4. Tanaka, K.; Wang, H.O. Fuzzy Control Systems Design and Analysis: A Linear Matrix Inequality Approach; John Wiley \& Sons: Hoboken, NJ, USA, 2004. [CrossRef]

5. Jadbabaie, A.; Jamshidi, M.; Titli, A. Guaranteed-cost design of continuous-time Takagi-Sugeno fuzzy controllers via linear matrix inequalities. In Proceedings of the IEEE International Conference on Fuzzy Systems Proceedings, IEEE World Congress on Computational Intelligence, Anchorage, AK, USA, 4-9 May 1998; Volume 1, pp. 268-273.

6. Ohtake, H.; Tanaka, K.; Wang, H.O. Fuzzy modeling via sector nonlinearity concept. Integr. Comput.-Aided Eng. 2003, 10, 333-341. [CrossRef]

7. Ichalal, D.; Marx, B.; Ragot, J.; Maquin, D. State estimation of Takagi-Sugeno systems with unmeasurable premise variables. IET Control Theory Appl. 2010, 4, 897-908. [CrossRef]

8. Lendek, Z.; Guerra, T.M.; Babuska, R.; De Schutter, B. Stability Analysis and Nonlinear Observer Design Using Takagi-Sugeno Fuzzy Models; Springer: Berlin/Heidelberg, Germany, 2011. [CrossRef]

9. López-Estrada, F.R.; Astorga-Zaragoza, C.M.; Theilliol, D.; Ponsart, J.C.; Valencia-Palomo, G.; Torres, L. Observer synthesis for a class of Takagi-Sugeno descriptor system with unmeasurable premise variable. Application to fault diagnosis. Int. J. Syst. Sci. 2017, 48, 3419-3430. [CrossRef]

10. Wang, Z.; Li, F.; Qin, Y.; Li, D.; Ma, G.; Ma, J. A Novel Dual Nonlinear Observer for Vehicle System Roll Behavior With Lateral and Vertical Coupling; SAE Technical Paper; SAE International: Warrendale, PA, USA, 2019. [CrossRef]

11. Nagy Kiss, A.M.; Marx, B.; Mourot, G.; Schutz, G.; Ragot, J. State estimation of two-time scale multiple models. Application to wastewater treatment plant. Control Eng. Pract. 2011, 19, 1354-1362. [CrossRef]

12. López-Estrada, F.R.; Ponsart, J.C.; Astorga-Zaragoza, C.M.; Camas-Anzueto, J.L.; Theilliol, D. Robust sensor fault estimation for descriptor-LPV systems with unmeasurable gain scheduling functions: Application to an anaerobic bioreactor. Int. J. Appl. Math. Comput. Sci. 2015, 25, 233-244. [CrossRef]

13. Zhao, Z.; Wang, Y.; Liu, F. A multi-way LPV modeling method for batch processes. J. Process Control 2018, 65, 56-67. [CrossRef] 
14. Gómez-Peñate, S.; López-Estrada, F.R.; Valencia-Palomo, G.; Rotondo, D.; Enríquez-Zárate, J. Actuator and sensor fault estimation based on a proportional-integral quasi-LPV observer with inexact scheduling parameters. In Proceedings of the 3rd IFAC Workshop on Linear Parameter-Varying Systems, Eindhoven, The Netherlands, 4-6 November 2019.

15. Lopez-Estrada, F.R.; Astorga-Zaragoza, C.M.; Valencia-Palomo, G.; Rios-Rojas, C.; Galicia-Gonzalez, C.; Escobar-Gomez, E. Observer-based LPV stabilization system for a riderless bicycle. IEEE Latin Am. Trans. 2018, 16, 1076-1083. [CrossRef]

16. López-Estrada, F.R.; Theilliol, D.; Astorga-Zaragoza, C.M.; Ponsart, J.C.; Valencia-Palomo, G.; Camas Anzueto, J. Fault diagnosis observer for descriptor Takagi-Sugeno systems. Neurocomputing 2019, 331, 10-17. [CrossRef]

17. Pfifer, H.; Moreno, C.P.; Theis, J.; Kotikapuldi, A.; Gupta, A.; Takarics, B.; Seiler, P. Linear parameter varying techniques applied to aeroservoelastic aircraft: In memory of Gary Balas. IFAC-PapersOnLine 2015, 48, 103-108. [CrossRef]

18. Huang, B.; Lu, B.; Li, Q. A proportional-integral-based robust state-feedback control method for linear parameter-varying systems and its application to aircraft. Proc. Inst. Mech. Eng. Part G 2019, 233, 4663-4675. [CrossRef]

19. Gutjahr, B.; Gröll, L.; Werling, M. Lateral vehicle trajectory optimization using constrained linear time-varying MPC. IEEE Trans. Intell. Transp. Syst. 2016, 18, 1586-1595. [CrossRef]

20. Gómez-Peñate, S.; López-Estrada, F.R.; Valencia-Palomo, G.; Osornio-Ríos, R.; Zepeda-Hernández, J.; Rios-Rojas, C.; Camas-Anzueto, J. Sensor fault diagnosis observer for an electric vehicle modeled as a Takagi-Sugeno system. J. Sens. 2018, 2018, 3291639. [CrossRef]

21. Chadli, M.; Borne, P. Multiple Models Approach in Automation: Takagi-Sugeno Fuzzy Systems; Wiley Online Library: London, UK, 2013. [CrossRef]

22. Rotondo, D. Advances in Gain-Scheduling and Fault Tolerant Control Techniques; Springer: Cham, Switzerland, 2017. [CrossRef]

23. Bernal, M.; Estrada, V.; Márquez, R. Diseño e Implementación de Sistemas de Control Basados en Estructuras Convexas Y Desigualdades Matriciales Lineales; Pearson: México city, Mexico, 2019.

24. Rodrigues, M.; Hamdi, H.; BenHadj-Braiek, N.; Theilliol, D. Observer-based fault tolerant control design for a class of LPV descriptor systems. J. Frankl. Inst. 2014, 351, 3104-3125. [CrossRef]

25. Rotondo, D.; Nejjari, F.; Puig, V. Quasi-LPV modeling, identification and control of a twin rotor MIMO system. Control Eng. Pract. 2013, 21, 829-846. [CrossRef]

26. Rotondo, D.; Nejjari, F.; Puig, V. Robust quasi-LPV model reference FTC of a quadrotor UAV subject to actuator faults. Int. J. Appl. Math. Comput. Sci. 2015, 25, 7-22. [CrossRef]

27. He, D.F.; Huang, H.; Chen, Q.X. Quasi-min-max MPC for constrained nonlinear systems with guaranteed input-to-state stability. J. Frankl. Inst. 2014, 351, 3405-3423. [CrossRef]

28. He, Z.; Zhao, L. Quadrotor trajectory tracking based on quasi-LPV system and internal model control. Math. Probl. Eng. 2015, 2015, 857291. [CrossRef]

29. Rizzello, G.; Naso, D.; Turchiano, B.; Seelecke, S. Robust position control of dielectric elastomer actuators based on LMI optimization. IEEE Trans. Control Syst. Technol. 2016, 24, 1909-1921. [CrossRef]

30. Rizzello, G.; Ferrante, F.; Naso, D.; Seelecke, S. Robust interaction control of a dielectric elastomer actuator with variable stiffness. IEEE/ASME Trans. Mech. 2017, 22, 1705-1716. [CrossRef]

31. Pérez-Estrada, A.J.; Osorio-Gordillo, G.L.; Darouach, M.; Alma, M.; Olivares-Peregrino, V.H. Generalized dynamic observers for quasi-LPV systems with unmeasurable scheduling functions. Int. J. Robust Nonlinear Control 2018, 28, 5262-5278. [CrossRef]

32. Robles, R.; Sala, A.; Bernal, M. Performance-oriented quasi-LPV modeling of nonlinear systems. Int. J. Robust Nonlinear Control 2019, 29, 1230-1248. [CrossRef]

33. Baranyi, P. Extracting LPV and qLPV structures from state-space functions: A TP model transformation based framework. IEEE Trans. Fuzzy Syst. 2019. [CrossRef]

34. Rotondo, D.; Puig, V.; Nejjari, F.; Witczak, M. Automated generation and comparison of Takagi-Sugeno and polytopic quasi-LPV models. Fuzzy Sets Syst. 2015, 277, 44-64. [CrossRef]

35. López-Estrada, F.R.; Ponsart, J.C.; Theilliol, D.; Zhang, Y.; Astorga-Zaragoza, C.M. LPV model-based tracking control and robust sensor fault diagnosis for a quadrotor UAV. J. Intell. Robot. Syst. 2016, 84, 163-177. [CrossRef] 
36. Ramírez, M.; Villafuerte, R.; González, T.; Bernal, M. Exponential estimates of a class of time-delay nonlinear systems with convex representations. Int. J. Appl. Math. Comput. Sci. 2015, 25, 815-826. [CrossRef]

37. Arceo, J.C.; Vázquez, D.; Estrada-Manzo, V.; Márquez, R.; Bernal, M. Nonlinear convex control of the Furuta pendulum based on its descriptor model. In Proceedings of the 13th International Conference on Electrical Engineering, Computing Science and Automatic Control (CCE), Mexico City, Mexico, 26-30 September 2016; pp. 1-6.

38. Quintana, D.; Estrada-Manzo, V.; Bernal, M. A methodology for real-time implementation of nonlinear observers via convex optimization. In Proceedings of the 15th International Conference on Electrical Engineering, Computing Science and Automatic Control (CCE), Mexico City, Mexico, 5-7 September 2018; pp. 1-6.

39. Arceo, J.C.; Sánchez, M.; Estrada-Manzo, V.; Bernal, M. Convex stability analysis of nonlinear singular systems via linear matrix inequalities. IEEE Trans. Autom. Control 2018, 64, 1740-1745. [CrossRef]

40. López-Estrada, F.R.; Hernández-de León, H.R.; Estrada-Manzo, V.; Bernal, M. LMI-based fault detection and isolation of nonlinear descriptor systems. In Proceedings of the IEEE International Conference on Fuzzy Systems (FUZZ-IEEE), Naples, Italy, 9-12 July 2017; pp. 1-5.

41. Hoffmann, C.; Werner, H. A survey of linear parameter-varying control applications validated by experiments or high-fidelity simulations. IEEE Trans. Control Syst. Technol. 2014, 23, 416-433. [CrossRef]

42. Apkarian, P.; Biannic, J.M.; Gahinet, P. Self-scheduled $H_{\infty}$ control of missile via linear matrix inequalities. J. Guid. Control Dyn. 1995, 18, 532-538. [CrossRef]

43. Rugh, W.J.; Shamma, J.S. Research on gain scheduling. Automatica 2000, 36, 1401-1425. [CrossRef]

44. Shamma, J.S.; Athans, M. Gain scheduling: Potential hazards and possible remedies. IEEE Control Syst. Mag. 1992, 12, 101-107.

45. Rotondo, D.; Nejjari, F.; Puig, V. Robust state-feedback control of uncertain LPV systems: An LMI-based approach. J. Frankl. Inst. 2014, 351, 2781-2803. [CrossRef]

46. Sato, M. Gain-scheduled output-feedback controllers depending solely on scheduling parameters via parameter-dependent Lyapunov functions. Automatica 2011, 47, 2786-2790. [CrossRef]

47. Sato, M.; Peaucelle, D. Gain-scheduled output-feedback controllers using inexact scheduling parameters for continuous-time LPV systems. Automatica 2013, 49, 1019-1025. [CrossRef]

48. Kajiwara, H.; Apkarian, P.; Gahinet, P. LPV Techniques for Control of an Inverted Pendulum. IEEE Control Syst. 1999, 19, 44-54.

49. Bruzelius, F.; Breitholtz, C.; Pettersson, S. LPV-based gain scheduling technique applied to a turbo fan engine model. In Proceedings of the International Conference on Control Applications, Glasgow, UK, 18-20 September 2002; pp. 713-718.

50. Scherer, C.W. Robust Mixed Control and LPV Control with Full Block Scaling; Technical Report; Delft University of Technology, Mechanical Engineering Systems and Control Group: Delft, The Netherlands, 2004.

51. Mohammadpour, J.; Scherer, C. Control of Linear Parameter Varying Systems with Applications; Springer: New York, NY, USA, 2012. [CrossRef]

52. Xu, H.E.; Jun, Z.; M, D.G.; Chao, C. Switching control for LPV polytopic systems using multiple Lyapunov functions. In Proceedings of the 30th Chinese Control Conference, Yantai, China, 22-24 July 2011; pp. 1771-1776.

53. Xu, H.E.; Jun, Z.; Dimirovski, G.M. A blending method control of switched LPV systems with slow-varying parameters and its application to an F-16 aircraft model. In Proceedings of the 30th Chinese Control Conference, Yantai, China, 22-24 July 2011; pp. 1765-1770.

54. Shin, J.; Balas, G.; Kaya, A.M. Blending methodology of linear parameter varying control synthesis of F-16 aircraft system. J. Guid. Control Dyn. 2002, 25, 1040-1048. [CrossRef]

55. Xie, W.; Kamiya, Y.; Eisaka, T. Robust control system design for polytopic stable LPV systems. IMA J. Math. Control Inf. 2003, 20, 201-216. [CrossRef]

56. Qiu, J.; Feng, G.; Gao, H. Fuzzy-Model-Based Piecewise $H_{\infty}$ Static-Output-Feedback Controller Design for Networked Nonlinear Systems. IEEE Trans. Fuzzy Syst. 2010, 18, 919-934. [CrossRef]

57. Yin, X.; Zhang, L.; Zhu, Y.; Wang, C.; Li, Z. Robust control of networked systems with variable communication capabilities and application to a semi-active suspension system. IEEE/ASME Trans. Mech. 2016, 21, 2097-2107. [CrossRef] 
58. Shamma, J.S. Analysis and Design of Gain Scheduled Control Systems. Ph.D. Thesis, Massachusetts Institute of Technology, Cambridge, MA, USA, 1988.

59. Shamma, J.S.; Athans, M. Guaranteed properties of gain scheduled control for linear parameter-varying plants. Automatica 1991, 27, 559-564. [CrossRef]

60. Goebel, R.; Hu, T.; Teel, A.R. Dual matrix inequalities in stability and performance analysis of linear differential/difference inclusions. In Current Trends in Nonlinear Systems and Control; Springer: Boston, MA, USA, 2006; pp. 103-122. [CrossRef]

61. Apkarian, P.; Gahinet, P.; Becker, G. Self-scheduled $\mathrm{H}_{\infty}$ control of linear parameter-varying systems: A design example. Automatica 1995, 31, 1251-1261. [CrossRef]

62. Pandey, A.; Sehr, M.; de Oliveira, M. Pre-filtering in gain-scheduled and robust control. In Proceedings of the American Control Conference (ACC), Boston, MA, USA, 6-8 July 2016; pp. 3698-3703.

63. Sehr, M.A.; de Oliveira, M.C. Pre-filtering and post-filtering in gain-scheduled output-feedback control. Int. J. Robust Nonlinear Control 2017, 27, 3259-3279. [CrossRef]

64. Sala, A.; Arino, C. Asymptotically necessary and sufficient conditions for stability and performance in fuzzy control: Applications of Polya's theorem. Fuzzy Sets Syst. 2007, 158, 2671-2686. [CrossRef]

65. Kruszewski, A.; Sala, A.; Guerra, T.M.; Ariño, C. A triangulation approach to asymptotically exact conditions for fuzzy summations. IEEE Trans. Fuzzy Syst. 2009, 17, 985-994. [CrossRef]

66. Sala, A.; Arino, C. Relaxed stability and performance LMI conditions for Takagi-Sugeno fuzzy systems with polynomial constraints on membership function shapes. IEEE Trans. Fuzzy Syst. 2008, 16, 1328-1336. [CrossRef]

67. Tuan, H.D.; Apkarian, P.; Narikiyo, T.; Yamamoto, Y. Parameterized linear matrix inequality techniques in fuzzy control system design. IEEE Trans. Fuzzy Syst. 2001, 9, 324-332. [CrossRef]

68. Wang, H.O.; Tanaka, K.; Griffin, M. Parallel distributed compensation of nonlinear systems by Takagi-Sugeno fuzzy model. In Proceedings of the 1995 IEEE International Conference on Fuzzy Systems, Yokohama, Japan, 20-24 March 1995; Volume 2, pp. 531-538.

69. Wang, L.K.; Zhang, H.G.; Liu, X.D. $H_{\infty}$ Observer Design for Continuous-Time Takagi-Sugeno Fuzzy Model with Unknown Premise Variables via Nonquadratic Lyapunov Function. IEEE Trans. Cybern. 2016, 46, 1986-1996. [CrossRef]

70. Márquez, R.; Guerra, T.M.; Bernal, M.; Kruszewski, A. A non-quadratic Lyapunov functional for $H_{\infty}$ control of nonlinear systems via Takagi-Sugeno models. J. Frankl. Inst. 2016, 353, 781-796. [CrossRef]

71. Márquez, R.; Guerra, T.M.; Bernal, M.; Kruszewski, A. Asymptotically necessary and sufficient conditions for Takagi-Sugeno models using generalized non-quadratic parameter-dependent controller design. Fuzzy Sets Syst. 2017, 306, 48-62. [CrossRef]

72. Pandey, A.; de Oliveira, M.C. Quadratic and poly-quadratic discrete-time stabilizability of linear parameter-varying systems. IFAC-PapersOnLine 2017, 50, 8624-8629. [CrossRef]

73. Lam, H.K.; Wu, L.; Zhao, Y. Linear matrix inequalities-based membership-function-dependent stability analysis for non-parallel distributed compensation fuzzy-model-based control systems. IET Control Theory Appl. 2014, 8, 614-625. [CrossRef]

74. Cherifi, A.; Guelton, K.; Arcese, L. Quadratic design of d-stabilizing non-pdc controllers for quasi-lpv/ts models. IFAC-PapersOnLine 2015, 48, 164-169. [CrossRef]

75. Guerra, T.M.; Bernal, M.; Guelton, K.; Labiod, S. Non-quadratic local stabilization for continuous-time Takagi-Sugeno models. Fuzzy Sets Syst. 2012, 201, 40-54. [CrossRef]

76. Daafouz, J.; Bernussou, J. Parameter dependent Lyapunov functions for discrete time systems with time varying parametric uncertainties. Syst. Control Lett. 2001, 43, 355-359. [CrossRef]

77. Chadli, M.; Daafouz, J.; Darouach, M. Stabilisation of singular LPV systems. IFAC Proc. Vol. 2008, 41, 9999-10002. [CrossRef]

78. Pandey, A.P.; de Oliveira, M.C. On the necessity of LMI-based design conditions for discrete time LPV filters. IEEE Trans. Autom. Control 2018, 63, 3187-3188. [CrossRef]

79. El Ghaoui, L.; Oustry, F.; AitRami, M. A cone complementarity linearization algorithm for static output-feedback and related problems. IEEE Trans. Autom. Control 1997, 42, 1171-1176. [CrossRef]

80. Prempain, E.; Postlethwaite, I. Static $H_{\infty}$ loop shaping control of a fly-by-wire helicopter. Automatica 2005, 41, 1517-1528. [CrossRef] 
81. Henrion, D.; Lasserre, J.B. Convergent relaxations of polynomial matrix inequalities and static output feedback. IEEE Trans. Autom. Control 2006, 51, 192-202. [CrossRef]

82. Apkarian, P.; Noll, D. Nonsmooth $H_{\infty}$ synthesis. IEEE Trans. Autom. Control 2006, 51, 71-86. [CrossRef]

83. Scherer, C.; Gahinet, P.; Chilali, M. $H_{\infty}$ design with pole placement constraints: An LMI approach. IEEE Trans. Autom. Control 1996, 41, 358-367.

84. Gahinet, P. Explicit controller formulas for LMI-based $\mathrm{H}_{\infty}$ synthesis. Automatica 1996, 32, 1007-1014. [CrossRef]

85. Amato, F. Robust Control of Linear Systems Subject to Uncertain Time-Varying Parameters; Springer: Berlin/Heidelberg, Germany, 2006; Volume 325. [CrossRef]

86. Kose, I.E.; Jabbari, F. Control of LPV systems with partly measured parameters. IEEE Trans. Autom. Control 1999, 44, 658-663. [CrossRef]

87. Abdullah, A.; Zribi, M. Model reference control of LPV systems. J. Frankl. Inst. 2009, 346, 854-871. [CrossRef]

88. Rotondo, D.; Puig, V.; Nejjari, F.; Romera, J. A fault-hiding approach for the switching quasi-LPV fault-tolerant control of a four-wheeled omnidirectional mobile robot. IEEE Trans. Ind. Electron. 2014, 62, 3932-3944. [CrossRef]

89. Valencia-Palomo, G.; Rossiter, J.A. Auto-tuned predictive control based on minimal plant information. IFAC Proc. Vol. 2009, 42, 554-559. [CrossRef]

90. Valencia-Palomo, G.; Rossiter, J.; López-Estrada, F. Improving the feed-forward compensator in predictive control for setpoint tracking. ISA Trans. 2014, 53, 755-766. [CrossRef] [PubMed]

91. Valencia-Palomo, G.; Hilton, K.; Rossiter, J.A. Predictive control implementation in a PLC using the IEC 1131.3 programming standard. In Proceedings of the 2009 European Control Conference (ECC), Budapest, Hungary, 23-26 August 2009; pp. 1317-1322.

92. Kothare, M.V.; Balakrishnan, V.; Morari, M. Robust constrained model predictive control using linear matrix inequalities. Automatica 1996, 32, 1361-1379. [CrossRef]

93. Lu, Y.; Arkun, Y. Quasi-min-max MPC algorithms for LPV systems. Automatica 2000, 36, 527-540. [CrossRef]

94. Park, P.; Jeong, S.C. Constrained RHC for LPV systems with bounded rates of parameter variations. Automatica 2004, 40, 865-872. [CrossRef]

95. Lu, Y.; Arkun, Y. Polytope updating in quasi-min-max MPC algorithms. IFAC Proc. Vol. 2000, 33, 407-412. [CrossRef]

96. Lu, Y.; Arkun, Y. A scheduling quasi-min-max model predictive control algorithm for nonlinear systems. J. Process Control 2002, 12, 589-604. [CrossRef]

97. Lee, S.; Won, S. Model predictive control for linear parameter varying systems using a new parameter dependent terminal weighting matrix. IEICE Trans. Fund. Electron. Commun. Comput. Sci. 2006, 89, 2166-2172. [CrossRef]

98. Wada, N.; Saito, K.; Saeki, M. Model predictive control for linear parameter varying systems using parameter dependent Lyapunov function. IEEE Trans. Circuits Syst. II 2006, 12, 1446-1450. [CrossRef]

99. Pluymers, B.; Rossiter, J.; Suykens, J.; De Moor, B. The efficient computation of polyhedral invariant sets for linear systems with polytopic uncertainty. In Proceedings of the American Control Conference, Portland, OR, USA, 8-10 June 2005; pp. 804-809. [CrossRef]

100. Garone, E.; Casavola, A. Receding horizon control strategies for constrained LPV systems based on a class of nonlinearly parameterized Lyapunov functions. IEEE Trans. Autom. Control 2012, 57, 2354-2360. [CrossRef]

101. Yu, S.; Böhm, C.; Chen, H.; Allgöwer, F. Model predictive control of constrained LPV systems. Int. J. Control 2012, 85, 671-683. [CrossRef]

102. Besselmann, T.; Lofberg, J.; Morari, M. Explicit MPC for LPV systems: Stability and optimality. IEEE Trans. Autom. Control 2012, 57, 2322-2332. [CrossRef]

103. Zhang, J.; Xiu, X. Kd tree based approach for point location problem in explicit model predictive control. J. Frankl. Inst. 2018, 355, 5431-5451. [CrossRef]

104. Ariño, C.; Querol, A.; Sala, A. Shape-independent model predictive control for Takagi-Sugeno fuzzy systems. Eng. Appl. Artif. Intell. 2017, 65, 493-505. [CrossRef]

105. Hanema, J.; Lazar, M.; Tóth, R. Stabilizing tube-based model predictive control: Terminal set and cost construction for LPV systems. Automatica 2017, 85, 137-144. [CrossRef]

106. Ding, B.; Wang, P.; Hu, J. Dynamic output feedback robust MPC with one free control move for LPV model with bounded disturbance. Asian J. Control 2018, 20, 755-767. [CrossRef] 
107. Morato, M.M.; Nguyen, M.Q.; Sename, O.; Dugard, L. Design of a fast real-time LPV model predictive control system for semi-active suspension control of a full vehicle. J. Frankl. Inst. 2019, 356, 1196-1224. [CrossRef]

108. Ghersin, A.S.; Pena, R.S.S. Applied LPV control with full block multipliers and regional pole placement. J. Control Sci. Eng. 2010, 2010, 3. [CrossRef]

109. Ostertag, E. Mono-and Multivariable Control and Estimation: Linear, Quadratic and LMI Methods; Springer: Berlin/Heidelberg, Germany, 2011. [CrossRef]

110. Rotondo, D.; Puig, V.; Nejjari, F. Linear quadratic control of LPV systems using static and shifting specifications. In Proceedings of the European Control Conference (ECC), Linz, Austria, 15-17 July 2015; pp. 3085-3090.

111. Briat, C. Stability analysis and control of a class of LPV systems with piecewise constant parameters. Syst. Control Lett. 2015, 82, 10-17. [CrossRef]

112. Bruzelius, F.; Pettersson, S.; Breitholtz, C. Region of attraction estimates for LPV-gain scheduled control systems. In Proceedings of the European Control Conference (ECC), Cambridge, UK, 1-4 September 2003; pp. 892-897. [CrossRef]

113. Pitarch, J.L.; Sala, A.; Arino, C.V. Closed-form estimates of the domain of attraction for nonlinear systems via fuzzy-polynomial models. IEEE Trans. Cybern. 2013, 44, 526-538. [CrossRef]

114. Lendek, Z.; Lauber, J. Local stability of discrete-time TS fuzzy systems. IFAC-PapersOnLine 2016, 49, 7-12. [CrossRef]

115. Lendek, Z.; Nagy, Z.; Lauber, J. Local stabilization of discrete-time TS descriptor systems. Eng. Appl. Artif. Intell. 2018, 67, 409-418. [CrossRef]

116. Zhang, X.; Tsiotras, P.; Knospe, C. Stability analysis of LPV time-delayed systems. Int. J. Control 2002, 75, 538-558. [CrossRef]

117. Wu, F.; Grigoriadis, K.M. LPV systems with parameter-varying time delays: Analysis and control. Automatica 2001, 37, 221-229. [CrossRef]

118. Briat, C.; Sename, O.; Lafay, J.F. Memory-resilient gain-scheduled state-feedback control of uncertain LTI/LPV systems with time-varying delays. Syst. Control Lett. 2010, 59, 451-459. [CrossRef]

119. Briat, C. Linear Parameter-Varying and Time-Delay Systems: Analysis, Observation, Filtering Control; Springer: Berlin/Heidelberg, Germany, 2014; Volume 3. [CrossRef]

120. Guzmán-Rabasa, J.A.; López-Estrada, F.R.; González-Contreras, B.M.; Valencia-Palomo, G.; Chadli, M.; Pérez-Patricio, M. Actuator fault detection and isolation on a quadrotor unmanned aerial vehicle modeled as a linear parameter-varying system. Meas. Control 2019. [CrossRef]

121. Zhang, H.; Zhang, G.; Wang, J. $H_{\infty}$ Observer Design for LPV Systems With Uncertain Measurements on Scheduling Variables: Application to an Electric Ground Vehicle. IEEE/ASME Trans. Mech. 2016, 21, 1659-1670. [CrossRef]

122. Li, H.; Wu, C.; Yin, S.; Lam, H.K. Observer-based fuzzy control for nonlinear networked systems under unmeasurable premise variables. IEEE Trans. Fuzzy Syst. 2015, 24, 1233-1245. [CrossRef]

123. Ibrir, S.; Sabir, A. Robust observer-based stabilization and tracking of uncertain linear systems with $\mathcal{L} 2$-gain performance: Application to DC motors. In Proceedings of the 2016 IEEE International Energy Conference (ENERGYCON), Leuven, Belgium, 4-8 April 2016; pp. 1-6. [CrossRef]

124. Gauterin, E.; Kammerer, P.; Kühn, M.; Schulte, H. Effective wind speed estimation: Comparison between Kalman Filter and Takagi-Sugeno observer techniques. ISA Trans. 2016, 62, 60-72. [CrossRef]

125. Brizuela-Mendoza, J.A.; Astorga-Zaragoza, C.M.; Zavala-Río, A.; Pattalochi, L.; Canales-Abarca, F. State and actuator fault estimation observer design integrated in a riderless bicycle stabilization system. ISA Trans. 2016, 61, 199-210. [CrossRef]

126. Bergsten, P.; Palm, R.; Driankov, D. Observers for Takagi-Sugeno fuzzy systems. IEEE Trans. Syst. Man Cybern. Part B 2002, 32, 114-121. [CrossRef]

127. Zhang, L.; Yin, X.; Ning, Z.; Ye, D. Robust filtering for a class of networked nonlinear systems with switching communication channels. IEEE Trans. Cybern. 2016, 47, 671-682. [CrossRef]

128. Gómez-Peñate, S.; Valencia-Palomo, G.; López-Estrada, F.R.; Astorga-Zaragoza, C.M.; Osornio-Rios, R.A.; Santos-Ruiz, I. Sensor fault diagnosis based on a sliding mode and unknown input observer for Takagi-Sugeno systems with uncertain premise variables. Asian J. Control 2019, 21, 339-353. [CrossRef] 
129. Busawon, K.K.; Kabore, P. Disturbance attenuation using proportional integral observers. Int. J. Control 2001, 74, 618-627. [CrossRef]

130. Youssef, T.; Chadli, M.; Karimi, H.R.; Zelmat, M. Design of unknown inputs proportional integral observers for TS fuzzy models. Neurocomputing 2014, 123, 156-165. [CrossRef]

131. Kang, D. Design of a disturbance observer for discrete-time linear systems. In Proceedings of the 14th International Conference on Control, Automation and Systems (ICCAS), Seoul, South Korea, 22-25 October 2014; pp. 1381-1383.

132. Xu, J.; Mi, C.C.; Cao, B.; Deng, J.; Chen, Z.; Li, S. The state of charge estimation of lithium-ion batteries based on a proportional-integral observer. IEEE Trans. Veh. Technol. 2013, 63, 1614-1621.

133. Youssef, T.; Chadli, M.; Karimi, H.R.; Wang, R. Actuator and sensor faults estimation based on proportional integral observer for TS fuzzy model. J. Frankl. Inst. 2017, 354, 2524-2542. [CrossRef]

134. Rotondo, D.; Cristofaro, A.; Johansen, T.A.; Nejjari, F.; Puig, V. Detection of icing and actuators faults in the longitudinal dynamics of small UAVs using an LPV proportional integral unknown input observer. In Proceedings of the 3rd Conference on Control and Fault-Tolerant Systems (SysTol), Barcelona, Spain, 7-9 Deptember 2016; pp. 690-697. [CrossRef]

135. Rotondo, D.; López-Estrada, F.R.; Nejjari, F.; Ponsart, J.C.; Theilliol, D.; Puig, V. Actuator multiplicative fault estimation in discrete-time LPV systems using switched observers. J. Frankl. Inst. 2016, 353, 3176-3191. [CrossRef]

136. Duan, G.R. Analysis and Design of Descriptor Linear Systems; Springer: New York, NY, USA, 2010. [CrossRef]

137. Masubuchi, I.; Kato, J.; Saeki, M.; Ohara, A. Gain-scheduled controller design based on descriptor representation of LPV systems: Application to flight vehicle control. In Proceedings of the 43rd IEEE Conference on Decision and Control (CDC), Nassau, Bahamas, 14-17 December 2004; Volume 1, pp. 815-820.

138. Baghaee, H.R.; Mirsalim, M.; Gharehpetian, G.B.; Talebi, H.A. A generalized descriptor-system robust $\mathrm{H}_{\infty}$ control of autonomous microgrids to improve small and large signal stability considering communication delays and load nonlinearities. Int. J. Electr. Power Energy Syst. 2017, 92, 63-82. [CrossRef]

139. González, A.; Estrada-Manzo, V.; Guerra, T.M. Gain-scheduled $H_{\infty}$ admissibilisation of LPV discrete-time systems with LPV singular descriptor. Int. J. Syst. Sci. 2017, 48, 3215-3224. [CrossRef]

140. Arceo, J.C.; Villafuerte, R.; Estrada-Manzo, V.; Bernal, M. LMI-Based Controller Design for Time-Delay Nonlinear Descriptor Systems with Guaranteed Exponential Estimates. IFAC-PapersOnLine 2018, 51, 585-590. [CrossRef]

141. González, A.; Guerra, T.M. Enhanced Predictor-Based Control Synthesis for Discrete-Time TS Fuzzy Descriptor Systems With Time-Varying Input Delays. IEEE Trans. Fuzzy Syst. 2018, 27, 402-410. [CrossRef]

142. Guerra, T.M.; Estrada-Manzo, V.; Lendek, Z. Observer design for Takagi-Sugeno descriptor models: An LMI approach. Automatica 2015, 52, 154-159. [CrossRef]

143. Estrada-Manzo, V.; Lendek, Z.; Guerra, T.M. Generalized LMI observer design for discrete-time nonlinear descriptor models. Neurocomputing 2016, 182, 210-220. [CrossRef]

144. Hamdi, H.; Rodrigues, M.; Mechmeche, C.; Theilliol, D. Fault detection and isolation for linear parameter varying descriptor systems via proportional integral observer. Int. J. Adapt. Control Signal Proc. 2012, 26, 224-240. [CrossRef]

145. Alwi, H.; Edwards, C. Fault tolerant longitudinal aircraft control using non-linear integral sliding mode. IET Control Theory Appl. 2014, 8, 1803-1814. [CrossRef]

146. Gertler, J. Fault Detection and Diagnosis; John Wiley \& Sons, Ltd.: Hoboken, NJ, USA, 2008. [CrossRef]

147. Wei, X.; Verhaegen, M. LMI solutions to the mixed $H_{\infty} / H_{-}$fault detection observer design for linear parameter-varying systems. Int. J. Adapt. Control Signal Proc. 2011, 25, 114-136. [CrossRef]

148. Chadli, M.; Abdo, A.; Ding, S.X. $H_{-} / H_{\infty}$ fault detection filter design for discrete-time Takagi-Sugeno fuzzy system. Automatica 2013, 49, 1996-2005. [CrossRef]

149. Chibani, A.; Chadli, M.; Shi, P.; Braiek, N.B. Fuzzy fault detection filter design for T-S fuzzy systems in the finite-frequency domain. IEEE Trans. Fuzzy Syst. 2016, 25, 1051-1061. [CrossRef]

150. Wang, Z.; Shi, P.; Lim, C.C. $H_{-} / H_{\infty}$ fault detection observer in finite frequency domain for linear parameter-varying descriptor systems. Automatica 2017, 86, 38-45. [CrossRef]

151. Chibani, A.; Chadli, M.; Ding, S.X.; Braiek, N.B. Design of robust fuzzy fault detection filter for polynomial fuzzy systems with new finite frequency specifications. Automatica 2018, 93, 42-54. [CrossRef] 
152. Iwasaki, T.; Hara, S. Generalized KYP lemma: Unified frequency domain inequalities with design applications. IEEE Trans. Autom. Control 2005, 50, 41-59. [CrossRef]

153. Estrada, F.L.; Ponsart, J.C.; Theilliol, D.; Astorga-Zaragoza, C.M. Robust $H_{-} / H_{\infty}$ fault detection observer design for descriptor-LPV systems with unmeasurable gain scheduling functions. Int. J. Control 2015, 88, 2380-2391. [CrossRef]

154. Darouach, M.; Zasadzinski, M.; Xu, S.J. Full-order observers for linear systems with unknown inputs. IEEE Trans. Autom. Control 1994, 39, 606-609. [CrossRef]

155. Rotondo, D.; Witczak, M.; Puig, V.; Nejjari, F.; Pazera, M. Robust unknown input observer for state and fault estimation in discrete-time Takagi-Sugeno systems. Int. J. Syst. Sci. 2016, 47, 3409-3424. [CrossRef]

156. Rotondo, D.; Cristofaro, A.; Johansen, T.A.; Nejjari, F.; Puig, V. Icing detection in unmanned aerial vehicles with longitudinal motion using an LPV unknown input observer. In Proceedings of the Conference on Control Applications (CCA), Sydney, Australia, 21-23 September 2015; pp. 984-989. [CrossRef]

157. Chadli, M.; Karimi, H.R. Robust observer design for unknown inputs Takagi-Sugeno models. IEEE Trans. Fuzzy Syst. 2012, 21, 158-164. [CrossRef]

158. Meyer, L.; Ichalal, D.; Vigneron, V. Interval observer for LPV systems with unknown inputs. IET Control Theory Appl. 2017, 12, 649-660. [CrossRef]

159. Rotondo, D.; Cristofaro, A.; Johansen, T.A.; Nejjari, F.; Puig, V. State estimation and decoupling of unknown inputs in uncertain LPV systems using interval observers. Int. J. Control 2018, 91, 1944-1961. [CrossRef]

160. Rotondo, D.; Cristofaro, A.; Johansen, T.A.; Nejjari, F.; Puig, V. Robust fault and icing diagnosis in unmanned aerial vehicles using LPV interval observers. Int. J. Robust Nonlinear Control 2018. [CrossRef]

161. Hassanabadi, A.H.; Shafiee, M.; Puig, V. Actuator fault diagnosis of singular delayed LPV systems with inexact measured parameters via PI unknown input observer. IET Control Theory Appl. 2017, 11, 1894-1903. [CrossRef]

162. Xu, F.; Tan, J.; Wang, Y.; Wang, X.; Liang, B.; Yuan, B. Robust fault detection and set-theoretic UIO for discrete-time LPV systems with state and output equations scheduled by inexact scheduling variables. IEEE Trans. Autom. Control 2019. [CrossRef]

163. Marx, B.; Ichalal, D.; Ragot, J.; Maquin, D.; Mammar, S. Unknown input observer for LPV systems. Automatica 2019, 100, 67-74. [CrossRef]

164. Rodrigues, M.; Hamdi, H.; Theilliol, D.; Mechmeche, C.; BenHadj Braiek, N. Actuator fault estimation based adaptive polytopic observer for a class of LPV descriptor systems. Int. J. Robust Nonlinear Control 2015, 25, 673-688. [CrossRef]

165. Chandra, K.P.B.; Alwi, H.; Edwards, C. Fault detection in uncertain LPV systems with imperfect scheduling parameter using sliding mode observers. Eur. J. Control 2017, 34, 1-15. [CrossRef]

166. Chen, L.; Edwards, C.; Alwi, H. Sensor fault estimation using LPV sliding mode observers with erroneous scheduling parameters. Automatica 2019, 101, 66-77. [CrossRef]

167. Zhang, K.; Jiang, B.; Shi, P.; Xu, J. Analysis and design of robust $H_{-} / H_{\infty}$ fault estimation observer with finite-frequency specifications for discrete-time fuzzy systems. IEEE Trans. Cybern. 2014, 45, 1225-1235. [CrossRef] [PubMed]

168. Xie, X.; Yue, D.; Zhang, H.; Xue, Y. Fault estimation observer design for discrete-time Takagi-Sugeno fuzzy systems based on homogenous polynomially parameter-dependent Lyapunov functions. IEEE Trans. Cybern. 2017, 47, 2504-2513. [CrossRef] [PubMed]

169. Lopez-Estrada, F.R.; Ponsart, J.C.; Theilliol, D.; Astorga-Zaragoza, C.; Flores-Montiel, M. Robust state and fault estimation observer for discrete-time D-LPV systems with unmeasurable gain scheduling functions. Application to a binary distillation column. IFAC-PapersOnLine 2015, 48, 1012-1017. [CrossRef]

170. Morato, M.M.; Sename, O.; Dugard, L.; Nguyen, M.Q. Fault estimation for automotive Electro-Rheological dampers: LPV-based observer approach. Control Eng. Pract. 2019, 85, 11-22. [CrossRef]

171. Morato, M.M.; Mendes, P.R.; Normey-Rico, J.E.; Bordons, C. Robustness conditions of LPV fault estimation systems for renewable microgrids. Int. J. Electr. Power Energy Syst. 2019, 111, 325-350. [CrossRef]

172. Morato, M.M.; Regner, D.J.; Mendes, P.R.; Normey-Rico, J.E.; Bordons, C. Fault analysis, detection and estimation for a microgrid via $H_{2} / H_{\infty}$ LPV observers. Int. J. Electr. Power Energy Syst. 2019, 105, 823-845. [CrossRef]

173. Li, X.R.; Bar-Shalom, Y. Multiple-model estimation with variable structure. IEEE Trans. Autom. Control 1996, 41, 478-493. 
174. Hassani, V.; Aguiar, A.P.; Athans, M.; Pascoal, A.M. Multiple model adaptive estimation and model identification usign a minimum energy criterion. In Proceedings of the American Control Conference (ACC), St. Louis, MO, USA, 10-12 June 2009; pp. 518-523. [CrossRef]

175. Xiong, K.; Wei, C.; Liu, L. Robust multiple model adaptive estimation for spacecraft autonomous navigation. Aerosp. Sci. Technol. 2015, 42, 249-258. [CrossRef]

176. Rotondo, D.; Hassani, V.; Cristofaro, A. A multiple model adaptive architecture for the state estimation in discrete-time uncertain LPV systems. In Proceedings of the American Control Conference (ACC), Seattle, WA, USA, 24-26 May 2017; pp. 2393-2398.

177. Rotondo, D.; Cristofaro, A.; Hassani, V.; Johansen, T.A. Icing diagnosis in unmanned aerial vehicles using an LPV multiple model estimator. IFAC-PapersOnLine 2017, 50, 5238-5243. [CrossRef]

178. Yang, G.H.; Wang, H. Fault detection and isolation for a class of uncertain state-feedback fuzzy control systems. IEEE Trans. Fuzzy Syst. 2014, 23, 139-151. [CrossRef]

179. Alwi, H.; Edwards, C.; Tan, C.P. Fault Detection and Fault-Tolerant Control Using Sliding Modes; Springer: London, UK, 2011. [CrossRef]

180. Sivrioglu, S.; Nonami, K. Sliding mode control with time-varying hyperplane for AMB systems. IEEE/ASME Trans. Mech. 1998, 3, 51-59. [CrossRef]

181. Alwi, H.; Edwards, C.; Stroosma, O.; Mulder, J.; Hamayun, M.T. Real-time implementation of an ISM fault-tolerant control scheme for LPV plants. IEEE Trans. Ind. Electron. 2014, 62, 3896-3905.

182. Hamayun, M.T.; Ijaz, S.; Bajodah, A.H. Output integral sliding mode fault tolerant control scheme for LPV plants by incorporating control allocation. IET Control Theory Appl. 2017, 11, 1959-1967. [CrossRef]

183. Selvaraj, P.; Kaviarasan, B.; Sakthivel, R.; Karimi, H.R. Fault-tolerant SMC for Takagi-Sugeno fuzzy systems with time-varying delay and actuator saturation. IET Control Theory Appl. 2017, 11, 1112-1123. [CrossRef]

184. Shin, J.Y.; Wu, N.E.; Belcastro, C. Adaptive linear parameter varying control synthesis for actuator failure. J. Guid. Control Dyn. 2004, 27, 787-794. [CrossRef]

185. Sloth, C.; Esbensen, T.; Stoustrup, J. Robust and fault-tolerant linear parameter-varying control of wind turbines. Mechatronics 2011, 21, 645-659. [CrossRef]

186. Jia, Q.; Chen, W.; Zhang, Y.; Li, H. Fault reconstruction and fault-tolerant control via learning observers in Takagi-Sugeno fuzzy descriptor systems with time delays. IEEE Trans. Ind. Electron. 2015, 62, 3885-3895. [CrossRef]

187. Li, X.; Zhu, F.; Chakrabarty, A.; Żak, S.H. Nonfragile fault-tolerant fuzzy observer-based controller design for nonlinear systems. IEEE Trans. Fuzzy Syst. 2016, 24, 1679-1689. [CrossRef]

188. Lan, J.; Patton, R.J. Integrated design of fault-tolerant control for nonlinear systems based on fault estimation and T-S fuzzy modeling. IEEE Trans. Fuzzy Syst. 2016, 25, 1141-1154. [CrossRef]

189. Li, X.; Lu, D.; Zeng, G.; Liu, J.; Zhang, W. Integrated fault estimation and non-fragile fault-tolerant control design for uncertain Takagi-Sugeno fuzzy systems with actuator fault and sensor fault. IET Control Theory Appl. 2017, 11, 1542-1553. [CrossRef]

190. Rotondo, D.; Nejjari, F.; Puig, V.; Blesa, J. Model reference FTC for LPV systems using virtual actuators and set-membership fault estimation. Int. J. Robust Nonlinear Control 2015, 25, 735-760. [CrossRef]

191. Nazari, R.; Seron, M.M.; De Doná, J.A. Fault-tolerant control of systems with convex polytopic linear parameter varying model uncertainty using virtual-sensor-based controller reconfiguration. Annu. Rev. Control 2013, 37, 146-153. [CrossRef]

192. Rotondo, D.; Nejjari, F.; Puig, V. A virtual actuator and sensor approach for fault tolerant control of LPV systems. J. Process Control 2014, 24, 203-222. [CrossRef]

193. Tabatabaeipour, S.M.; Stoustrup, J.; Bak, T. Fault-tolerant control of discrete-time LPV systems using virtual actuators and sensors. Int. J. Robust Nonlinear Control 2015, 25, 707-734. [CrossRef]

194. Rotondo, D.; Ponsart, J.C.; Nejjari, F.; Theilliol, D.; Puig, V. Virtual actuator-based FTC for LPV systems with saturating actuators and FDI delays. In Proceedings of the 3rd Conference on Control and Fault-Tolerant Systems (SysTol), Barcelona, Spain, 7-9 September 2016; pp. 831-837.

195. Witczak, P.; Luzar, M.; Witczak, M.; Korbicz, J. A robust fault-tolerant model predictive control for linear parameter-varying systems. In Proceedings of the 19th International Conference on Methods and Models in Automation and Robotics (MMAR), Miedzyzdroje, Poland, 2-5 September 2014; pp. 462-467.

196. Acevedo-Valle, J.M.; Puig, V.; Tornil-Sin, S.; Witczak, M.; Rotondo, D. Predictive Fault Tolerant Control for LPV systems using model reference. IFAC-PapersOnLine 2015, 48, 30-35. [CrossRef] 
197. Pour, F.K.; Puig, V.; Cembrano, G. Health-aware LPV-MPC based on system reliability assessment for drinking water networks. In Proceedings of the IEEE Conference on Control Technology and Applications (CCTA), Copenhagen, Denmark, 21-24 August 2018; pp. 187-192.

198. Pour, F.K.; Puig, V.; Cembrano, G. Health-aware LPV-MPC based on a reliability-based remaining useful life assessment. IFAC-PapersOnLine 2018, 51, 1285-1291. [CrossRef]

199. Wu, F.; Yang, X.H.; Packard, A.; Becker, G. Induced L2-norm control for LPV systems with bounded parameter variation rates. Int. J. Robust Nonlinear Control 1996, 6, 983-998. [CrossRef]

200. Packard, A. Gain scheduling via linear fractional transformations. Syst. Control Lett. 1994, $22,79-92$. [CrossRef]

201. Veenman, J.; Scherer, C.W. Stability analysis with integral quadratic constraints: A dissipativity based proof. In Proceedings of the 52nd IEEE Conference on Decision and Control, Florence, Italy, 10-13 December 2013; pp. 3770-3775.

202. Brizuela-Mendoza, J.; Sorcia-Vázquez, F.J.; Guzmán-Valdivia, C.H.; Osorio-Sánchez, R.; Martínez-García, M. Observer design for sensor and actuator fault estimation applied to polynomial LPV systems: A riderless bicycle study case. Int. J. Syst. Sci. 2018, 49, 2996-3006. [CrossRef]

203. Baranyi, P.; Yam, Y.; Várlaki, P. Tensor Product Model Transformation in Polytopic Model-Based Control; CRC Press: Boca Raton, FL, USA, 2013.

204. Takarics, B.; Baranyi, P. Tensor-product-model-based control of a three degrees-of-freedom aeroelastic model. J. Guid. Control Dyn. 2013, 36, 1527-1533. [CrossRef]

(C) 2019 by the authors. Licensee MDPI, Basel, Switzerland. This article is an open access article distributed under the terms and conditions of the Creative Commons Attribution (CC BY) license (http:/ / creativecommons.org/licenses/by/4.0/). 